\title{
Demonstration and Optimization of BNFL's Pulsed Jet Mixing and RFD Sampling Systems Using NCAW Simulant
}

Battelle

J.R. Bontha

G. R. Golcar

BNFL, Inc.

N. Hannigan

August 2000

Prepared for

BNFL, Inc.

under Contract W375-LC-98-4168

Battelle, Pacific Northwest Division

Richland, Washington 99352 


\section{DISCLAIMER}

This report was prepared as an account of work sponsored by an agency of the United States Government. Neither the United States Government nor any agency thereof, nor any of their employees, make any warranty, express or implied, or assumes any legal liability or responsibility for the accuracy, completeness, or usefulness of any information, apparatus, product, or process disclosed, or represents that its use would not infringe privately owned rights. Reference herein to any specific commercial product, process, or service by trade name, trademark, manufacturer, or otherwise does not necessarily constitute or imply its endorsement, recommendation, or favoring by the United States Government or any agency thereof. The views and opinions of authors expressed herein do not necessarily state or reflect those of the United States Government or any agency thereof. 


\section{DISCLAIMER}

Portions of this document may be illegible in electronic image products. Images are produced from the best available original document. 


\section{EXECUTIVE SUMMARY}

The BNFL Inc. flowsheet for the pretreatment and vitrification of the Hanford High Level Tank waste includes the use of several hundred Reverse Flow Diverters (RFDs) for sampling and transferring the radioactive slurries and Pulsed Jet mixers to homogenize or suspend the tank contents.

The Pulsed Jet mixing and the RFD sampling devices represent very simple and efficient methods to mix and sample slurries, respectively, using compressed air to achieve the desired operation. The equipment has no moving parts, which makes them very suitable for mixing and sampling highly radioactive wastes. However, the effectiveness of the mixing and sampling systems are yet to be demonstrated when dealing with Hanford slurries, which exhibit a wide range of physical and rheological properties.

This report describes the results of the testing of BNFL's Pulsed Jet mixing and RFD sampling systems in a 13-ft ID and 15-ft height dish-bottomed tank at Battelle's 336 building high-bay facility using AZ-101/102 simulants containing up to $36-\mathrm{wt} \%$ insoluble solids. The specific objectives of the work were to:

- Demonstrate the effectiveness of the Pulsed Jet mixing system to thoroughly homogenize Hanford-type slurries over a range of solids loading

- Minimize/optimize air usage by changing sequencing of the Pulsed Jet mixers or by altering cycle times

- Demonstrate that the RFD sampler can obtain representative samples of the slurry up to the maximum RPP-WTP baseline concentration of $25-w t \%$.

The viscosity of the simulant used was very close to the actual tank waste data, but the settling rate of the solids was four times faster than the actual tank waste.

The pulse jet mixers readily homogenized the supernate tank contents, at both 28 and $36-w t \%$ solids. There was some stratification in the top half of the tank at $17-w t \%$ solids. This small amount of stratification was due to the design of the pulse tubes being based on actual tank waste settling data rather than the simulant.

The scope of the work also included evaluating whether sequencing the operation or reducing the frequency of pulsing could optimize the air requirements to the pulse tubes. By sequencing the operation of the Pulsed Jet mixers, the simulant could be kept suspended quite readily. Since homogenization of tank contents is only required when sampling or possibly during transfers, therefore for general operations the Pulse Jet mixers may be sequenced. Sequencing of the Pulse Jet Mixers results in an $80 \%$ reduction in compressed air and associated vent requirements.

The RFD sample system had no difficulty in pumping all concentrations of the simulant tested, up to a height of $40 \mathrm{ft}$ through a $3 / 4$ inch pipe approximately 120 - $\mathrm{ft}$ long. A representative sample was taken by the sample Tee at $17-\mathrm{wt} \%$ and $28-\mathrm{wt} \%$ solids but the Tee was unable to produce a representative sample at $38 \mathrm{wt} \%$ solids due to the sample needle being too small. 


\section{ACKNOWLEDGEMENTS}

The authors wish to thank Dr. Steve Taylor, Mr. Anthony Dean and Mr. Peter Griffiths of AEA Technology for their valuable assistance during the planning, design, and testing phases of this work. 


\section{ACRONYMS}

$\begin{array}{ll}\text { ASME } & \text { American Society of Mechanical Engineers } \\ \text { BNFL } & \text { British Nuclear Fuels } \\ \text { GRE } & \text { Gas Release Event } \\ \text { HAST } & \text { Highly Active Storage Tanks } \\ \text { HEME } & \text { High Efficiency Mist Eliminator } \\ \text { HEPA } & \text { High Efficiency Particle Arrestor } \\ \text { HLW } & \text { Highly Active Waste } \\ \text { LAW } & \text { Low Active Waste } \\ \text { LPP } & \text { LAW Preatment Plant } \\ \text { NCAW } & \text { Neutralized Current Acid Waste } \\ \text { PNNL } & \text { Pacific Northwest National Laboratories } \\ \text { PJM } & \text { Pulse Jet Mixer } \\ \text { RFD } & \text { Reverse Flow Diverter } \\ \text { RPP-WTP } & \text { River Protection Project Waste Treatment Plant } \\ \text { SCFM } & \text { Standard Cubic Feet per Minute } \\ \text { THORP } & \text { Thermal Oxide Reprocessing Plant }\end{array}$




\section{TABLE OF CONTENTS}

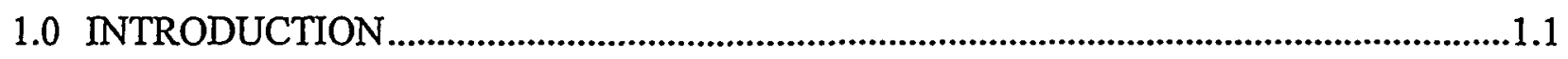

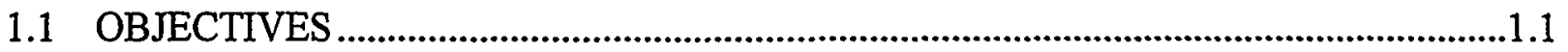

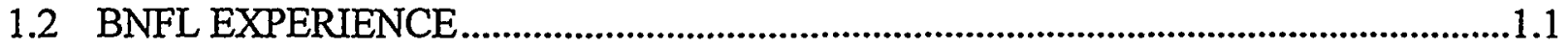

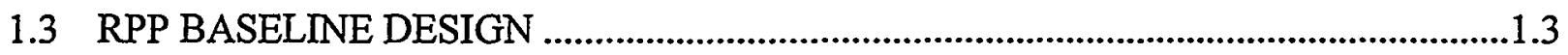

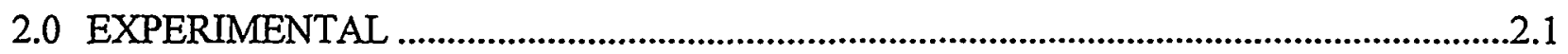

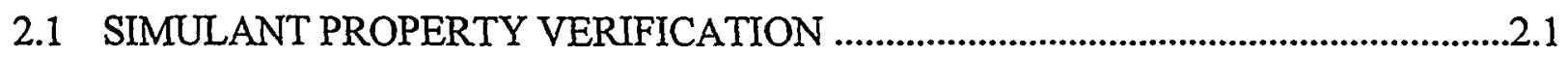

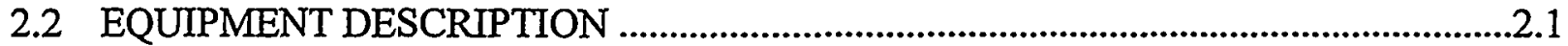

2.2.1 336 Building Test Facility and Supernate or Dish Bottomed Tank ......................2.1

2.2.2 Pulsed Jet Mixing and RFD Sampling Systems ....................................................2.3

2.2.3 Installation of the Pulsed Jet Mixing and RFD Sampling Systems in the

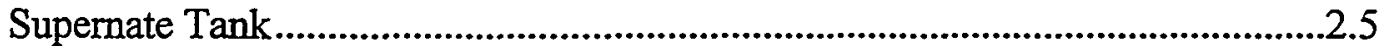

2.2.4 Slurry Monitoring Equipment ..................................................................2.8

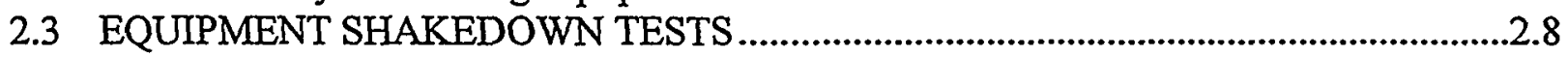

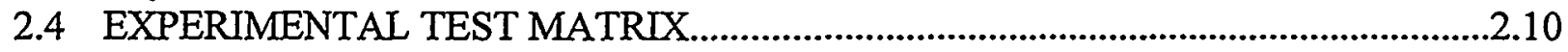

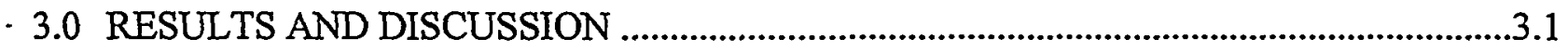

3.1 HOMOGENIZATION OF THE TANK CONTENTS ..........................................................

3.2 TIME TO ACHIEVE HOMOGENEITY ...........................................................................

3.3 RFD PERFORMANCE ................................................................................................

3.4 KEEPING SOLIDS SUSPENDED AT MINIMIZED AIR INPUT ....................................6

3.4.1 17-Wt\% Initial Solids Loading................................................................................

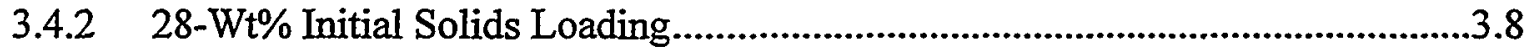

$3.4 .3 \quad 36-W t \%$ Solids Loading ..........................................................................................

3.5 IMPACT OF RESULTS ON PLANT DESIGN AND OPERATION ...............................10

3.5.1 Mixing of Tanks .........................................................................................10

3.5.2 Vent System.....................................................................................................11

3.5.3 Wash Down of Pulse Jet Mixers, RFD Airlines and Charge Vessels .................3.11

3.5.4 Cleaning of Autosampler T ...................................................................................12

3.5.5 Operation of RFDs ..............................................................................................1.

4.0 CONCLUSIONS AND RECOMMENDATIONS..............................................................

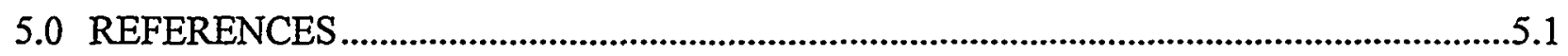

APPENDIX A: SIMULANT PROPERTY VERIFICATION ...................................................

APPENDIX B: MICROMOTION FUNCTION CHECK ..............................................................

APPENDIX C: PREPARATION OF THE SIMULANT ................................................................ 


\section{Figures}

Figure 1.1. Pulsed Jet Mixers and RFD's Installed in BNFL's Encapsulation Plant in Sellafield, UK.

Figure 1.2. Pulsed Jet Mixers in BNFL's Highly Active Liquid Storage Tanks ....................... 1.2

Figure 2.1. Photograph of the Supernate Tank in the 336-Building High Bay Facility at Battelle.

Figure 2.2. Photograph of the Pulse Tube provided by BNFL. .............................................2.3

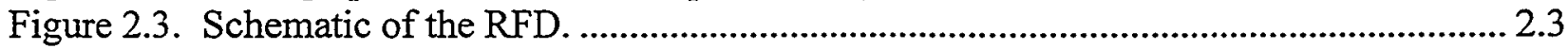

Figure 2.4. Photograph of the RFD Sampling Tee. ........................................................... 2.4

Figure 2.5. Schematic of the RFD Charge Vessel. .................................................................... 2.4

Figure 2.6. Photograph of Two Pulse Tubes and the RFD Charge Vessel Installed in the

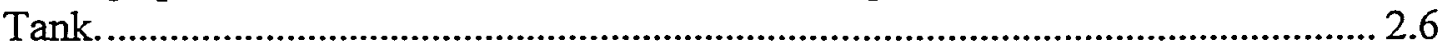

Figure 2.7. Photograph showing the Air/Vacuum Lines to the Pulse Tubes............................ 2.7

Figure 2.8. Schematic of the Sampling Arrangement Used to Measure the Slurry Concentration within the Tank.

Figure 3.1. Mixer Performance at Different Initial Solids Loading of 17 (Red), 28 (Yellow), and 36-wt\% (Blue) when All Four-Pulse Tubes Are Operated At Maximum Frequency.

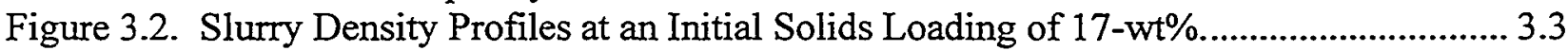

Figure 3.3. Average Solids Concentration Profiles at 17-wt\% Initial Solids Loading.............. 3.4

Figure 3.4. Average Solids Concentration Profiles at 17, 28, and 36-wt\% Initial Solids Loading.

Figure 3.5. Comparison of RFD Sample Density with that Obtained from the MicroMotion Density Meter Sample Drawn at the Same Location.

Figure 3.6. Mixing Profiles at 17-wt\% Initial Solids Loading. (a) Four (Red) and Two (Yellow) PJM Operating at Maximum Frequency of Operation. (b) Four PJM's Operating at 100 (Red), 50 (Yellow), and 10\% (Blue) of Maximum Frequency. (c) Two PJM's Operating at 100 (Red), 50 (Yellow), and 10\% (Blue) of Maximum Frequency. (d) One PJM Operating at 100 (Red), and $50 \%$ (Yellow) of Maximum Frequency.

Figure 3.7. Mixing Profiles at 28-wt\% Initial Solids Loading. (a) Four (Red), and One (Blue) PJM Operating at Maximum Frequency of Operation. (b) Four PJM's Operating at 100 (Red), 50 (Yellow), and 10\% (Blue) of Maximum Frequency. (c) Two PJM's Operating at 100 (Red), 50 (blue) of Maximum Frequency

Figure 3.8. Mixing Profiles for 36-Wt\% Initial Solids Loading. Curves in Red and Yellow are for 4 and 1 PJM Operated at Maximum Frequency. Blue Curve Represents the Data for 4 PJM at 50\% Frequency.

Figure 3.9. Photographs of the Air/Vacuum Lines Showing Slurry Coating at (a) Top of the Upper Cat Walk and (b) Control Module.

Figure A.1. Comparison of the Viscosity v. Shear Rate behavior for the Pulsed Jet and CUF Simulants with that of the Actual Waste.

Figure A.2. Comparison of the Settling Rate Behavior of the Pulsed Jet Simulant (in green) with that of the CUF Simulant (in Red) and the Actual Waste (in Blue). 


\section{TABLES}

Table 1.1. Typical RFD and Pulse Jet Mixer Applications at Sellafield.

Table 2.1. Experiments Performed to Evaluate the Pulsed Jet Mixing and RFD Sampling System..... 2.10

Table 3.1. Viscosity and Settling Rate Properties of the Three Simulated Slurries Tested in the Assessment of the Pulsed Jet Mixing and RFD Sampling Systems.........................................3.2

Table 3.2. Air Consumptions Requirements for Pulse Jet Mixers.......................................................... 3.11

Table B.1. Comparison of the Laboratory Sample Density with that measured by the MicroMotion Density Meter.

Table C.1. Amounts of the Total Solid and Liquid Phases Taken to Prepare The Slurries For The Pulsed Jet Mixer Testing, their Corresponding Solids Loading and Specific Gravity,

Table C.2. Amounts of the Individual Components Used to Make-up the Simulated Slurries Based on the AZ-101/102 Simulant Recipe Developed by Golcar et al. (2000). 


\subsection{INTRODUCTION}

The work described in this report involves the assessment of the performance of British Nuclear Fuels Limited (BNFL) Pulsed-Jet mixing and Reverse Flow Diverter (RFD) sampling systems in the 336 Building supernate tank using NCAW simulant.

\subsection{OBJECTIVES}

The specific objectives of the work were to:

- Demonstrate the effectiveness of the Pulsed Jet mixing system to thoroughly homogenize Hanford-type slurries over a range of solids loading

- Minimize/optimize air usage by changing sequencing of the Pulsed Jet mixers or by altering cycle times

- Demonstrate that the RFD sampler can obtain representative samples of the slurry up to the maximum RPP-WTP baseline concentration of $25-w t \%$.

\subsection{BNFL EXPERIENCE}

BNFL began developing RFD pumps and Pulse Jet Mixers in the 1970s to be used in the Thermal Oxide Reprocessing Plant (THORP) at Sellafield in the UK, for the transfer, mixing and sampling of highly active liquors during reprocessing operations. During the 1980 s, an extensive R\&D program was implemented which resulted in over 200 pumps and a large number of mixing systems being designed and installed into THORP.

RFDs and pulse jet mixers may now be found all over the Sellafield site. They are used on a variety of plants including the Vitrification and Encapsulation plants. Typical applications are listed in Table 1.1 and shown in Figures 1.1 and 1.2.

Table 1.1. Typical RFD and Pulse Jet Mixer Applications at Sellafield

\begin{tabular}{cc}
\hline System & Application \\
\hline RFD and RFD Autosampler & $20 \mathrm{wt} \%$ calciner dust \\
& Highly active liquor \\
& 7 Poise ferric floc \\
& $40 \mathrm{wt} \%$ barium carbonate \\
Pulse Jet Mixers & Azide destruction \\
& Highly active liquor \\
& $40 \mathrm{wt} \%$ barium carbonate \\
& $10 \mathrm{wt} \%$ magnox particles \\
& 7 poise ferric floc
\end{tabular}

In addition, pulse jet mixing has also been carried out on the Bethel Valley Storage Tanks at Oak Ridge and the C-Tanks. 


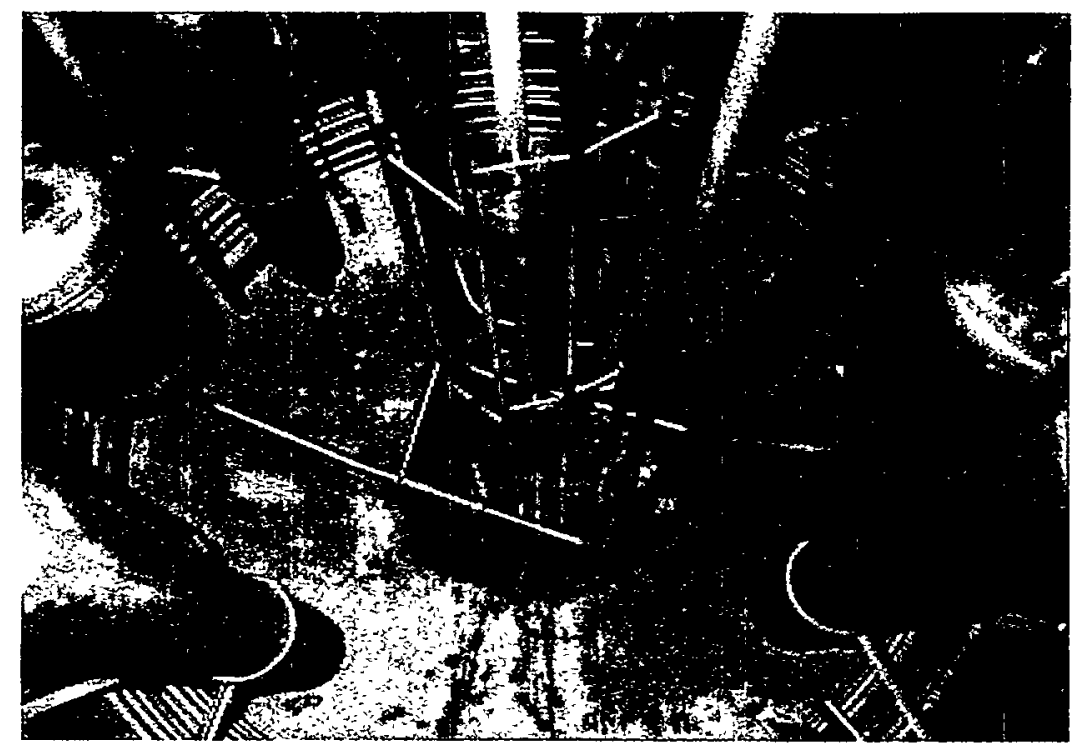

Figure 1.1. Pulsed Jet Mixers and RFD's Installed in BNFL's Encapsulation Plant in Sellafield, UK.

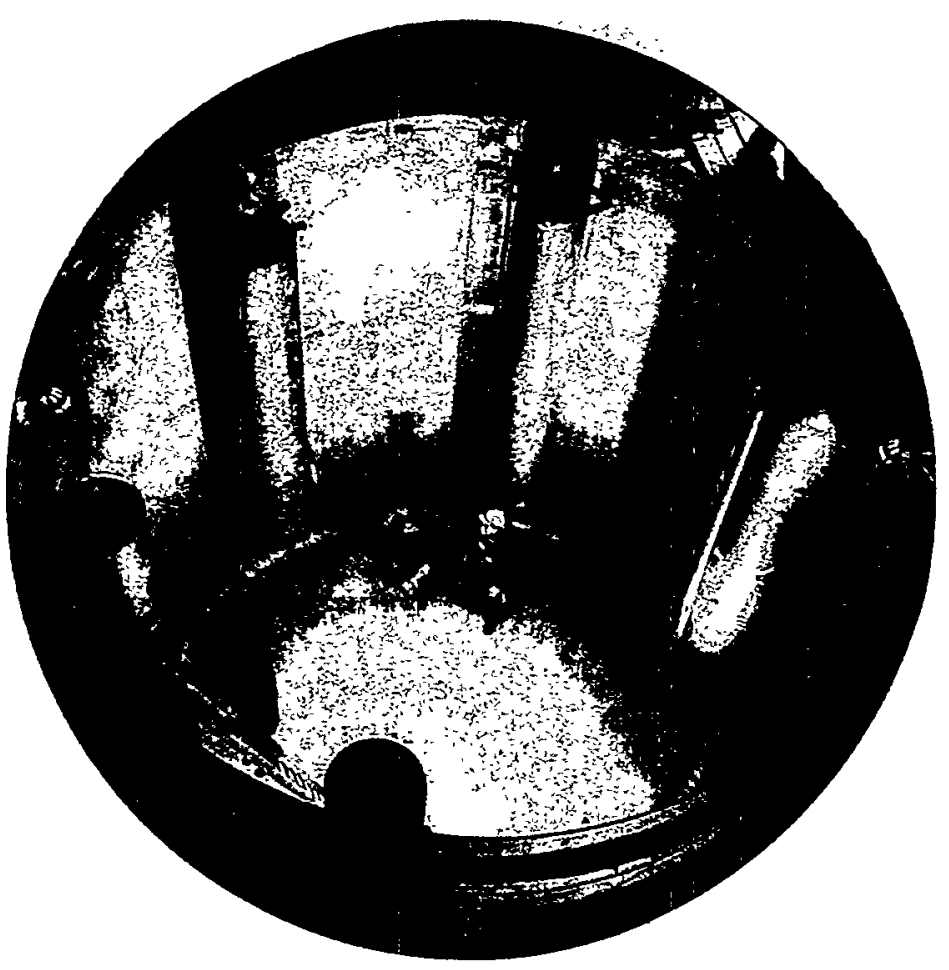

Figure 1.2. Pulsed Jet Mixers in BNFL's Highly Active Liquid Storage Tanks. 


\subsection{RPP BASELINE DESIGN}

Pulse Jet Mixing, RFDs and BNFL's sampling system are used extensively throughout RPP-WTP. The numbers of duties are summarized below:

- Pretreatment and LPP

$>49$ tanks containing 345 pulse jet mixers

$>157$ process RFDs

$>51$ sample RFDs

- HLW Vitrification

7 tanks containing 28 pulse jet mixers

20 process RFDs (including RFDs for agitation)

$>7$ sample RFDs

Pulse Jet Mixers and RFDs were chosen because they have a number of advantages over conventional pumps and agitators in an active environment. They contain no moving parts within the active cell, which means zero in-cell maintenance. With zero in-cell maintenance, operator dose is drastically reduced. Zero in-cell maintenance also means lifetime costs of RFDs and Pulse Jet Mixers are low because no spares are required and there is no secondary waste generated.

As mentioned above, BNFL has experience of pumping, sampling and mixing slurries up to 7 poise viscosity and containing up to $40 \mathrm{wt} \%$ solids. The maximum viscosity that will be encountered by pulse jet mixers or RFDs in RPP-WTP is 1 -poise, and the maximum solids concentration is 25 -wt\%. It is considered that there are no RFD pumping, sampling and pulse jet mixing duties identified for RPP-WTP which are outside BNFL's experience. 


\subsection{EXPERIMENTAL}

tasks:

The evaluation of the Pulsed Jet mixing and RFD sampling system consisted of three primary

1. Measurement of the physical and rheological properties of the simulant

2. Installation of the equipment for testing in the 336-building high-bay facility

3. Evaluation of the Pulsed Jet mixing and RFD sampling system.

The following sections describe the various tasks in more detail.

\subsection{SIMULANT PROPERTY VERIFICATION}

For the testing of the Pulsed-Jet mixing system and RFD sampling systems, BNFL identified the NCAW slurries to be indicative of some of the worst-case scenario conditions encountered during the Hanford waste processing. Hanford Tanks AZ-102/102 simulant developed by PNNL for the Crossflow Ultrafiltration equipment tests was chosen for the test work (Golcar et al. 2000). To simulate the washed solids, BNFL indicated that the aqueous phase of the simulant be water at $\mathrm{pH} 12$ (i.e. $0.01 \mathrm{M} \mathrm{NaOH}$ ).

The AZ-101/102 simulant consists of an aqueous phase with $0.8 \mathrm{M} \mathrm{NaNO}_{3}$ and $1.0 \mathrm{MNaOH}$. Although this simulant has been well characterized and its physical and rheological properties documented, changing the supernate phase to $\mathrm{pH} 12$ with no sodium nitrate could alter the properties of the simulant. Therefore, the scope of this task was to measure the physical and rheological properties of the $\mathrm{AZ}-101 / 102$ simulant at $\mathrm{pH} 12$ with no dissolved $\mathrm{NaNO}_{3}$ and to compare these properties with the CUF simulant and actual AZ-101/102 waste.

Since the Pulsed jet mixer performance depends upon the settling velocities, small-scale settling rate measurements were also conducted.

\subsection{EQUIPMENT DESCRIPTION}

BNFL provided the Pulsed-Jet mixing system and the RFD pump/sampler. Battelle's task was to install the mixing/sampling system, provide services, simulated slurry, and all other items necessary for conducting the testing. This section describes in detail the various equipment used for the testing

\subsubsection{Building Test Facility and Supernate or Dish Bottomed Tank}

The supernate or dish-bottomed tank in which the Pulsed Jet and RFD system evaluation was conducted was one of the three large-scale tanks available for PNNL clients to evaluate their test equipment and processes. The supernate tank was a cylindrical steel vessel of $\sim 13-\mathrm{ft}$ diameter and $15-\mathrm{ft}$ depth and is shown in Figure 2.1. The bottom of the tank was elliptically shaped with minimum and maximum radii of $\sim 3-\mathrm{ft}$ and $13-\mathrm{ft}$, respectively. A catwalk or observation bridge was present at height of 3 - $\mathrm{ft}$ from the top of the tank. The bridge contained a 2 - $\mathrm{ft} \times 2.5-\mathrm{ft}$ port (covered) for the installation of test equipment. Another catwalk (not shown in the figure) was present at an elevation of $\sim 40$-ft from the top of the tank and was used to support the air hoses to the Pulsed Jet tubes. There was a railing (not shown in Figure 2.1) along a $60^{\circ}$ section of the circumference of the tank about 3-ft below the top of the tank. An 
operator, standing on this railing, operated the Pulsed Jet mixing and RFD sampling system while observing the mixer performance from the top of the tank. Transfer pipes (not shown in the figure) at the top and at the bottom of the tank enable the addition or removal of material to and from the tank during loading or disposal operations. The supernate tank was positioned on three load gauges, which were used to accurately determine the weight of the tank and its contents to within 1-lb.

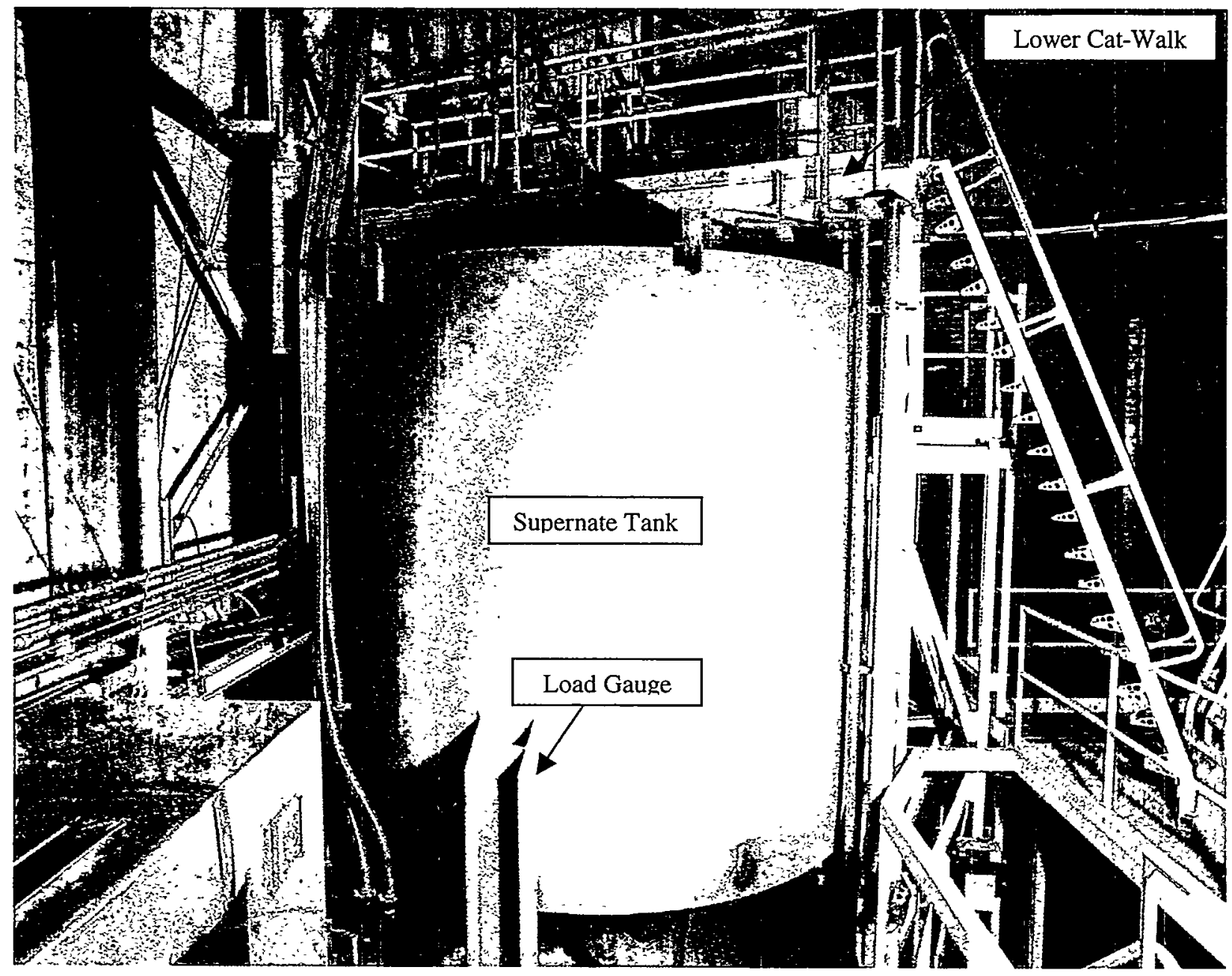

Figure 2.1. Photograph of the Supernate Tank in the 336-Building High Bay Facility at Battelle. 


\subsubsection{Pulsed Jet Mixing and RFD Sampling Systems}

The Pulsed Jet mixing system tested consisted of four pulse tubes each with a cylindrical section of 10-ft length and 2-ft internal diameter. Each tube is rounded at the top end with an opening for a 2 -in pipe connection. The bottom end of the pulse tube was tapered down a nozzle. The overall height of the pulse tube was approximately $12-\mathrm{ft}$ and is shown in Figure 2.2.

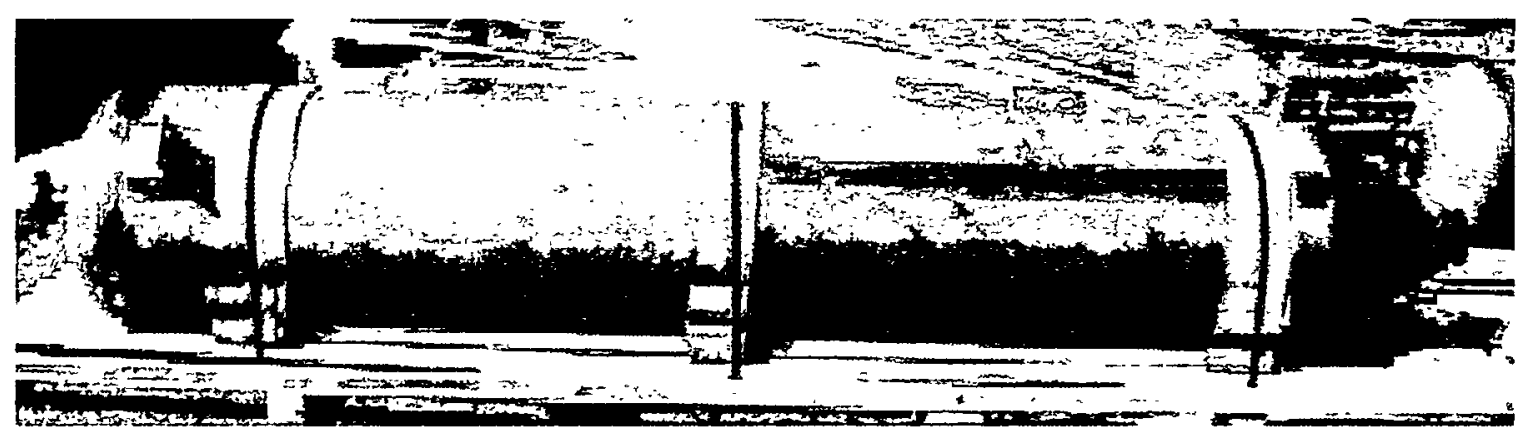

Figure 2.2. Photograph of the Pulse Tube provided by BNFL.

The RFD sample collection system, shown in Figures 2.3 to 2.5, consisted of three pieces:

1. RFD

2. Charge vessel

3. Sampling Tee

The RFD was primarily a venturi-type device with a hole drilled through its midsection to enable withdrawal of the slurry from the sampling location. The charge vessel consisted of a $\sim 1.7-\mathrm{ft}$ length and 1.5-ft $\mathrm{D}$ cylindrical vessel rounded at both ends. The top and bottom ends of the charge vessel are flanged to connect to $3 / 4^{\text {th }}$-in piping and the RFD sampler, respectively. The overall height of the charge vessel is $\sim 3.25$-ft. The sampling Tee is essentially a 3-way T-shaped valve device shown in Figure 2.4.

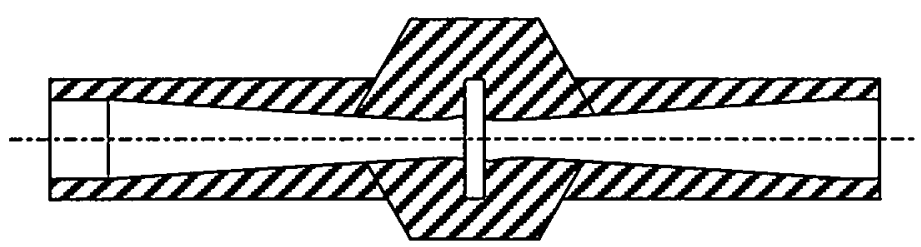

Figure 2.3. Schematic of the RFD. 


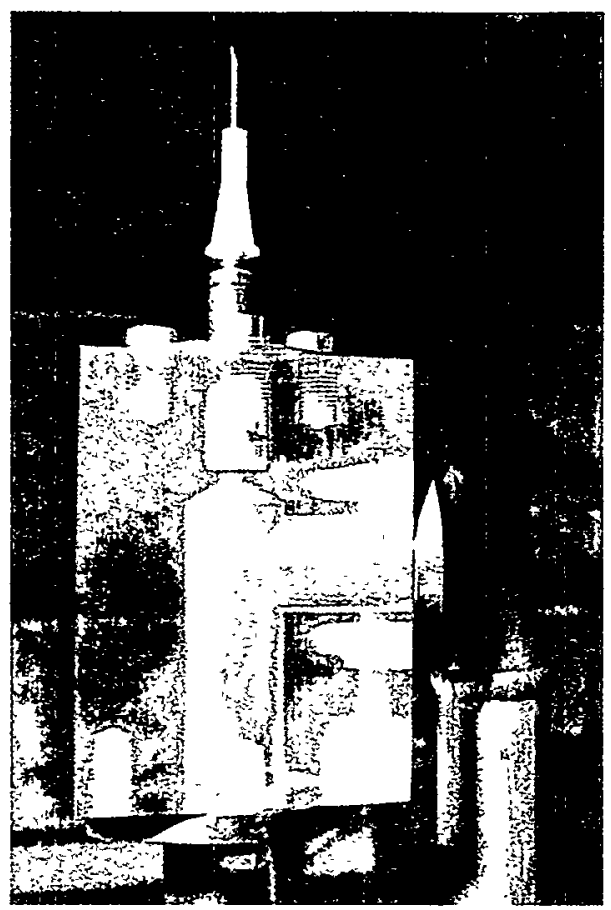

Figure 2.4. Photograph of the RFD Sampling Tee.

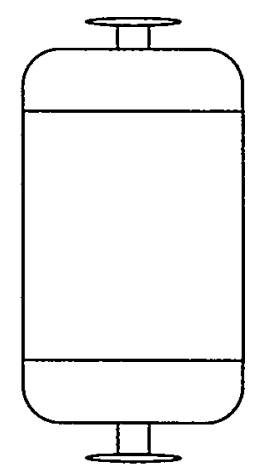

Figure 2.5. Schematic of the RFD Charge Vessel. 


\subsubsection{Installation of the Pulsed Jet Mixing and RFD Sampling Systems in the Supernate Tank}

The Pulsed Jet tubes and the RFD sampler/sampler were mounted on brackets positioned on top of the supernate tank. A photograph of two of the pulse tubes and the RFD charge vessel installed in the supernate tank is shown in Figure 2.6. Here cross beams, which traverse the length of the tank and welded to the sides, bear the weight of the Pulsed Jet tubes and the RFD sampler. The Pulsed Jet tubes were positioned at the center of the four quadrants of the supernate tank at approximately 6-in from the bottom of the tank. The charge vessel was positioned between one pair of the pulse tubes and the RFD was piped from the charge vessel to the sampling valve in such a manner that it was located at the $\sim 1$-ft above the bottom of the tank.

In order to simulate actual sampling during waste processing in the BNFL pretreatment facilities, the RFD sample Tee was located at an elevation of $\sim 40$-ft. For this reason, the RFD sampling Tee was located on the fourth floor of the 336 building high-bay area. The assembly to support the Pulsed Jet tubes has been designed by BNFL and Battelle's engineering staff to ensure compliance to all safety limits reviewed the drawings/design calculations.

The suction or discharge of the slurry to and from the pulse tubes and RFD charge vessel is regulated by Jet pump pairs present in a control module located on the ground level at the side of the tank. The jet pump pairs were connected to the pulse tubes using 2-in ID, wire reinforced, PVC tubing. In the case of the RFD, which required smaller diameter tubing, a braided PVC tubing of $3 / 4$-in ID was used.

A compressor/accumulator combination was used to regulate the airflow to the jet pump pairs. The compressor chosen for the present study based on the requirements for the air flow to the jet pump pairs was a IngerSol Model HP850WCU compressor capable of delivering 850-cfm at a operating pressure of 100-psig (7-barg). The accumulator was an ASME standard 240-gal Brunner vertical air-receiver tank with pressure relief valves and timed electronic drain valve. Both the compressor and the accumulator were located outside the 336 building facilitates.

During the suction phase, liquid in the pulse tubes piping can raise to a level of $\sim 20$-ft above the height of the liquid level. To prevent suction of the liquid into the vent, the jet-pump pairs may either be placed high enough above the pulse tubes or the air line between the jet-pump and the pulse tube may be luted. This is known as barometric protection. Although the RPP baseline design has jet-pump pairs placed on a floor above the pulse tubes, in this work the tubing connecting the jet pump pairs to the pulse tubes was routed to the upper catwalk located at $\sim 40-\mathrm{ft}$ from the top of the tank as shown in Figure 2.7. 


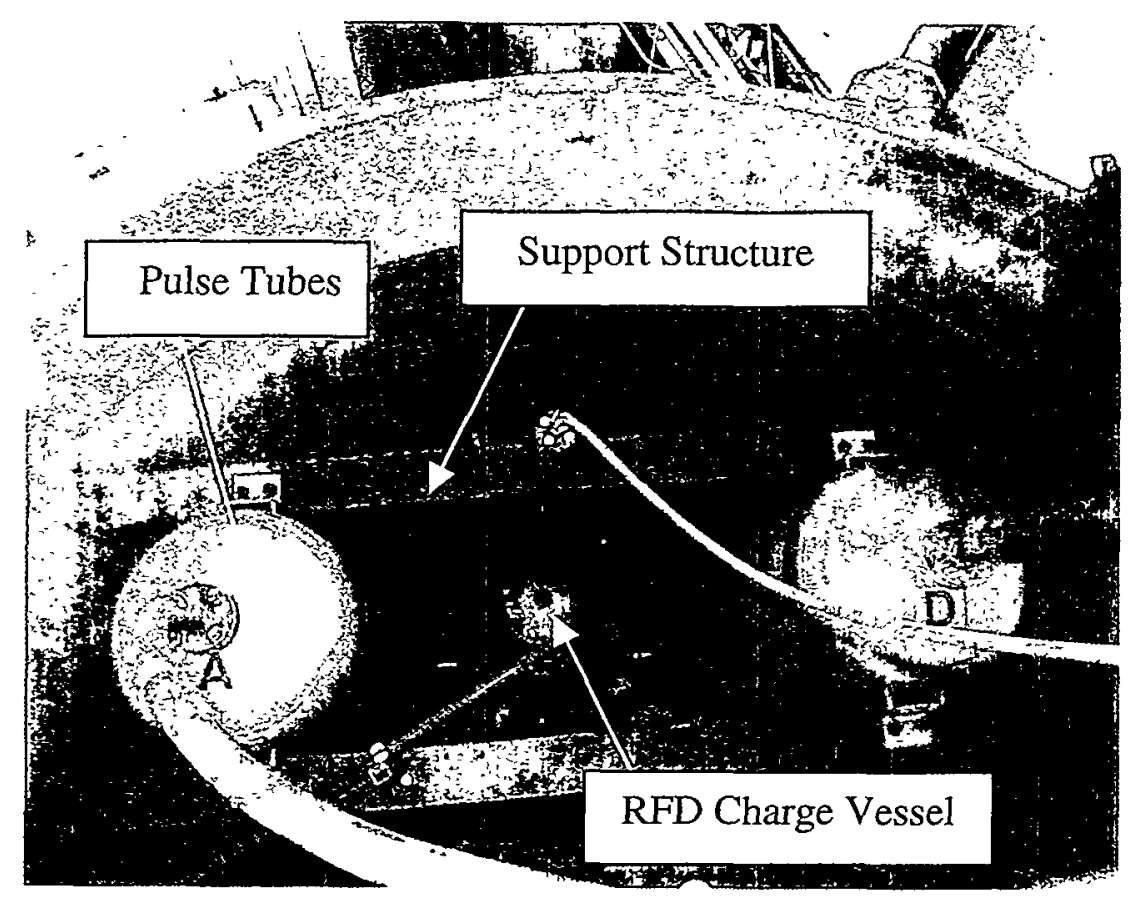

Figure 2.6. Photograph of Two Pulse Tubes and the RFD Charge Vessel Installed in the Tank.

The sequence of operation and cycle frequency of the Pulsed Jet mixers and RFD sampler was controlled by PRESCON ${ }^{\mathrm{TM}}$; an AEA Technology proprietary control system. PRESCON ${ }^{\mathrm{TM}}$ monitors pressure signals using pressure transmitters, which form part of the jet pump pair control module. These pressure signals are used to determine the state of operation of the Pulse Jet mixers and the RFD but most importantly, PRESCON ${ }^{\mathrm{TM}}$ monitors when a Pulsed Jet mixer or an RFD charge vessel is full. The measurement of vessel full is an important parameter during the operation of Pulsed Jet mixers and RFDs as it allows designers and operators to optimize performance of these systems. Vessel top-level measurement means that the size of charge vessels and Pulsed Jet mixers is minimized and air usage is optimized. PRESCONTM is non-intrusive and has no moving parts. 


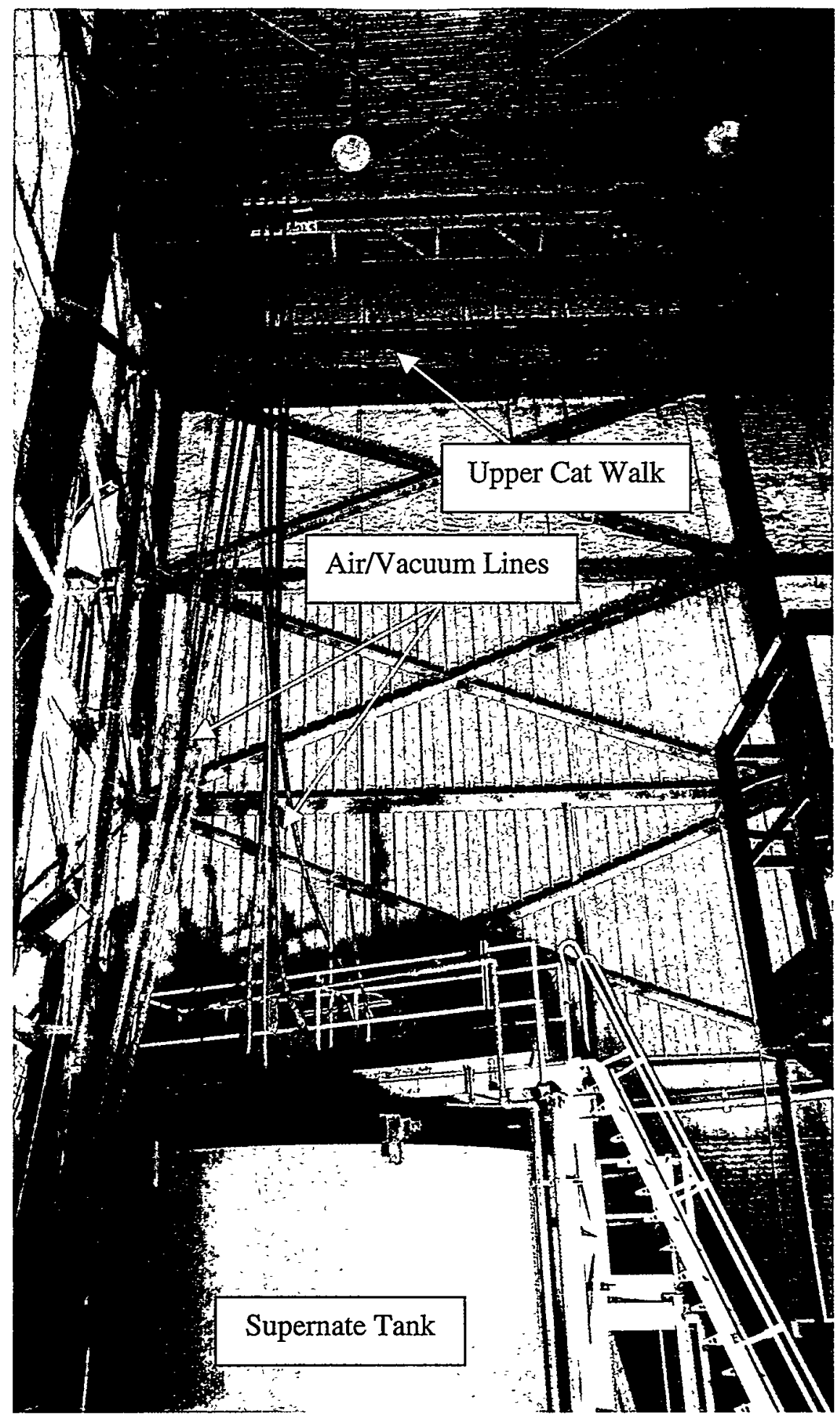

Figure 2.7. Photograph showing the Air/Vacuum Lines to the Pulse Tubes 


\subsubsection{Slurry Monitoring Equipment}

The density of the slurry at various locations within the tank was monitored continuously during the Pulsed Jet mixer operation using a MicroMotion density meter. The on-line slurry density monitoring equipment shown schematically in Figure 2.8 consists of recirculation pump, MicroMotion sensor, and a computer to record the data (not shown in Figure 2.8). All slurry monitoring equipment (except the computer) was installed on the observation bridge above the tank.

Slurry from the tank enters the pump inlet through any of the three 20 - $\mathrm{ft}$ long, 1 -in SS tubes. Opening and closing the appropriate control valves included in each line adjusted the line through which the slurry sample is collected. Each sample line had a provision by which the height at which the sample is collected can be adjusted. After the sample was analyzed, it was returned back to the tank. Using this configuration, density measurements were made at various depths and lateral positions to obtain a topographical representation of the slurry concentration profiles within the tank during the mixer operation.

\subsection{EQUIPMENT SHAKEDOWN TESTS}

After the installation of the support assembly, Pulsed Jet tubes, RFD sampler, and control modules, equipment shakedown tests using the tank filled with water were conducted. The purpose of the shakedown tests is to ensure that all equipment is working properly in order to prevent unwanted delays during testing phase. The system checks comprised of:

1. Leak tests

2. Compressor operation

3. Preliminary Pulsed Jet mixer operation and PRESCON ${ }^{\mathrm{TM}}$ parameter setup

4. Preliminary RFD sampler operation and PRESCON ${ }^{\mathrm{TM}}$ parameter setup

5. Functional operation of the Pulsed Jet mixer and RFD sampler operating simultaneously

6. MicroMotion function check 


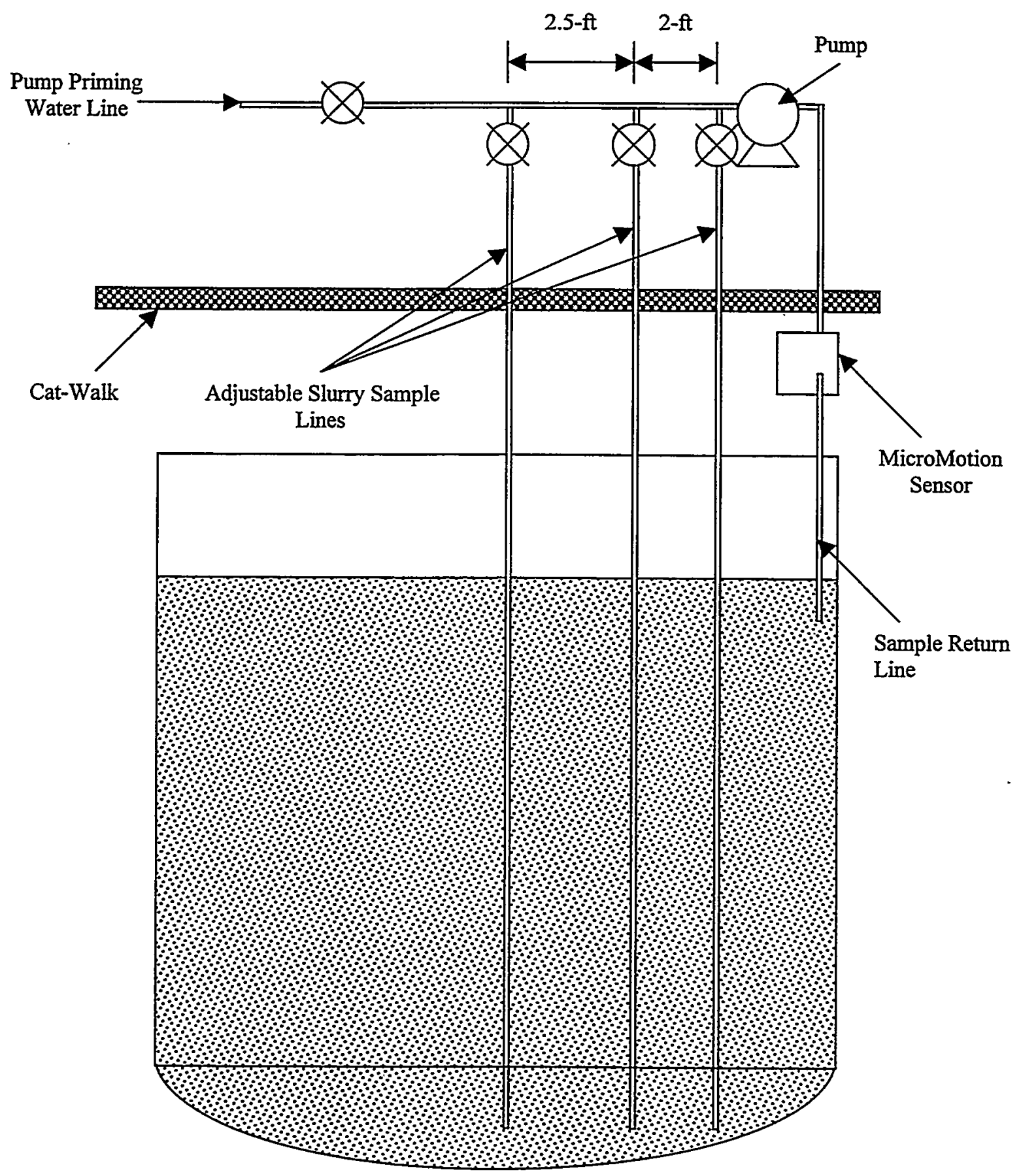

Figure 2.8. Schematic of the Sampling Arrangement Used to Measure the Slurry Concentration within the Tank. 


\section{$2.4 \cdot$ EXPERIMENTAL TEST MATRIX}

The performance of the Pulsed Jet mixing was evaluated using the three simulated slurries at different sequences of operation of the pulse tubes and varying frequencies of pulsing. Table 2.1 lists the various tests performed to evaluate the Pulsed Jet mixing and RFD sampling system and the objective of each test.

Table 2.1. Experiments Performed to Evaluate the Pulsed Jet Mixing and RFD Sampling System

\begin{tabular}{|c|c|c|c|c|}
\hline Number & Wt\% Solids Loading & Sequenc & Frequency & Objective \\
\hline 1 & $17 \%$ & $A+B+C+D$ & $100 \%$ & 4PJM@Max \\
\hline 2 & $17 \%$ & $A+C / B+D$ & $100 \%$ & 2PJM@Max after4 PJM@Max \\
\hline 3 & $17 \%$ & $A+B+C+D$ & $100 \%$ & Homogenize with 4 PJM@Max \\
\hline 4 & $17 \%$ & $\mathrm{~A}, \mathrm{~B}, \mathrm{C}, \mathrm{D}$ & $100 \%$ & 1PJM@Max after4 PJM@Max \\
\hline 5 & $17 \%$ & $A+B+C+D$ & $100 \%$ & Homogenize with 4 PJM @Max \\
\hline 6 & $17 \%$ & $A+B+C+D$ & $50 \%$ & 4 PJM@50\% after 4 PJM@Max \\
\hline 7 & $17 \%$ & $A+B+C+D$ & $100 \%$ & Homogenize with4 PJM@Max \\
\hline 8 & $17 \%$ & $\mathrm{~A}+\mathrm{C} / \mathrm{B}+\mathrm{D}$ & $50 \%$ & 2PJM@50\% after 4 PJM@Max \\
\hline 9 & $17 \%$ & $A+B+C+\bar{D}$ & $100 \%$ & Homogenize with4 PJM@Max \\
\hline 10 & $17 \%$ & $A, B, C, D$ & $50 \%$ & 1 PJM@50\% after $4 @ M a x$ \\
\hline 11 & $17 \%$ & $A+B+C+D$ & $100 \%$ & Homogenize with4 PJM@Max \\
\hline 12 & $17 \%$ & $A, B, C, D$ & $50 \%$ & 1PJM@50\% after4 PJM@Max \\
\hline 13 & $17 \%$ & $A+B+C+D$ & $100 \%$ & Homogenize with4 PJM@Max \\
\hline 14 & $17 \%$ & $\mathrm{~A}+\mathrm{B}+\mathrm{C}+\mathrm{D}$ & $10 \%$ & 4PJM@10\%after4 PJM@Max \\
\hline 15 & $17 \%$ & $A+C / B+D$ & $100 \%$ & 2PJM@Max \\
\hline 16 & $17 \%$ & $A+B+C+D$ & $100 \%$ & Homogenize with 4 PJM @ Max \\
\hline 17 & $17 \%$ & $A+C / B+D$ & $10 \%$ & 2 PJM@10\% after 4 PJM@max \\
\hline 18 & $17 \%$ & $\mathrm{~A}, \mathrm{~B}, \mathrm{C}, \mathrm{D}$ & $100 \%$ & 1 PJM@Max \\
\hline 19 & $28 \%$ & $A+B+C+D$ & $100 \%$ & 4PJM@Max \\
\hline 20 & $28 \%$ & $A+B+C+D$ & $50 \%$ & 4 PJM@50\% after 4 PJM @ Max \\
\hline 21 & $28 \%$ & $A+C / B+D$ & $100 \%$ & 2 PJM@Max \\
\hline 22 & $28 \%$ & $A+B+C+D$ & $100 \%$ & Homogenize with4 PJM@Max \\
\hline 23 & $28 \%$ & $A+C / B+D$ & $100 \%$ & 2 PJM@Max after 4 PJM @ Max \\
\hline 24 & $28 \%$ & $A+C / B+D$ & $50 \%$ & 2 PJM @50\% after 4 PJM @ Max \\
\hline 25 & $28 \%$ & $A+B+C+D$ & $100 \%$ & Homogenize with 4 PJM @ Max \\
\hline 26 & $28 \%$ & $\mathrm{~A}, \mathrm{~B}, \mathrm{C}, \mathrm{D}$ & $100 \%$ & 1 PJM@Max after4 PJM@Max \\
\hline 27 & $28 \%$ & $A+B+C+D$ & $100 \%$ & Homogenize with 4 PJM @ Max \\
\hline 28 & $28 \%$ & $A+B+C+D$ & $10 \%$ & 4 PJM@10\% after 4 PJM@ Max \\
\hline 29 & $36 \%$ & $A+B+C+D$ & $100 \%$ & 4 PJM@Max \\
\hline 30 & $36 \%$ & $A+B+C+D$ & $50 \%$ & 4 PJM@50\% after 4 PJM @ Max \\
\hline 31 & $36 \%$ & $A+B+C+D$ & $100 \%$ & 4 PJM@Max for Tour \\
\hline 32 & $36 \%$ & $A+B+C+D$ & $100 \%$ & Homogenize with 4 PJM @ Max \\
\hline 33 & $36 \%$ & $\mathrm{~A}, \mathrm{~B}, \mathrm{C}, \mathrm{D}$ & $100 \%$ & 1PJM@Max after4 PJM@Max \\
\hline
\end{tabular}


In Table 2.1, the operational sequences $A+B+C+D, A+C / B+D$, and $A, B, C, D$, respectively, represent the pulse tubes operating simultaneously, two at a time, and sequentially. Typical cycle time for the charging, discharging, and venting the pulse tubes are on the order of $\sim 90$-seconds which represents the $100 \%$ frequency of operation in Table 2.1 . Frequencies of $50 \%$ and $10 \%$ correspond to cycle times of 180 and 450 -seconds, respectively.

It can be seen from the list of experiments performed in Table 2.1, the 17-wt\% solids loading was most thoroughly investigated. Due to limited time availability, only a few select experiments were performed with the 28, and 36-wt\% initial solids loading system. Also, in a majority of all cases (except Runs 15,18 , and 21), the slurry was first thoroughly homogenized with four pulse tubes operating at maximum frequency before switching to a different operating sequence and/or frequency. The objective in these tests was to see if solids remain suspended with lower energy input to the system. For the case of experiment Runs 15,18 , and 21 , the objective of these tests was to investigate whether the system can be homogenized with fewer pulse tubes operating at a time at maximum frequency. 


\subsection{RESULTS AND DISCUSSION}

\subsection{HOMOGENIZATION OF THE TANK CONTENTS}

BNFL designed the Pulsed Jet mixing system to homogenize the contents of the tank when all four-pulse tubes are operated simultaneously at a specific frequency based on the settling data of the actual waste (Gray et al. 1990 and 1993). Here homogeneity at any location within the tank is defined by:

$$
\text { Homogeneity Index }(\%)=100 *\left[C_{a}\right] /\left[C_{e}\right]
$$

where $\mathrm{C}_{\mathrm{a}}$ is actual solids concentration (in wt\%) at the sampling location and $\mathrm{C}_{\mathrm{e}}$ (in wt\%) is the expected solids concentration if the contents of the tank were completely mixed. In Equation $1, C_{e}$ was computed from the measured density of slurry $(\rho)$ and the known densities of the supernatant $\left(\rho_{1} \sim 1 \mathrm{~g} / \mathrm{cm}^{3}\right)$ and solid phases $\left(\rho_{\mathrm{s}} \sim 3.2 \mathrm{~g} / \mathrm{cm}^{3}\right)$ using the following relationship:

$$
C_{a}(w t \%)=100 *\left[\left(1 / \rho_{l}\right)-(1 / \rho)\right] /\left[\left(1 / \rho_{l}\right)-\left(1 / \rho_{s}\right)\right]
$$

For the present discussion, the contents of the tank were considered to be completely homogeneous if the homogeneity index at all locations was between 95 and 105\%. Homogeneity is an important parameter when a representative sample is required during plant operations. At other times, the requirement is generally to keep the solids from settling.

The demonstration phase of mixer performance tests was conducted at the three different solids loadings of 17,28 , and $36-\mathrm{wt} \%$ with all four pulse tubes operating at maximum frequency and the results are illustrated in Figure 3.1.

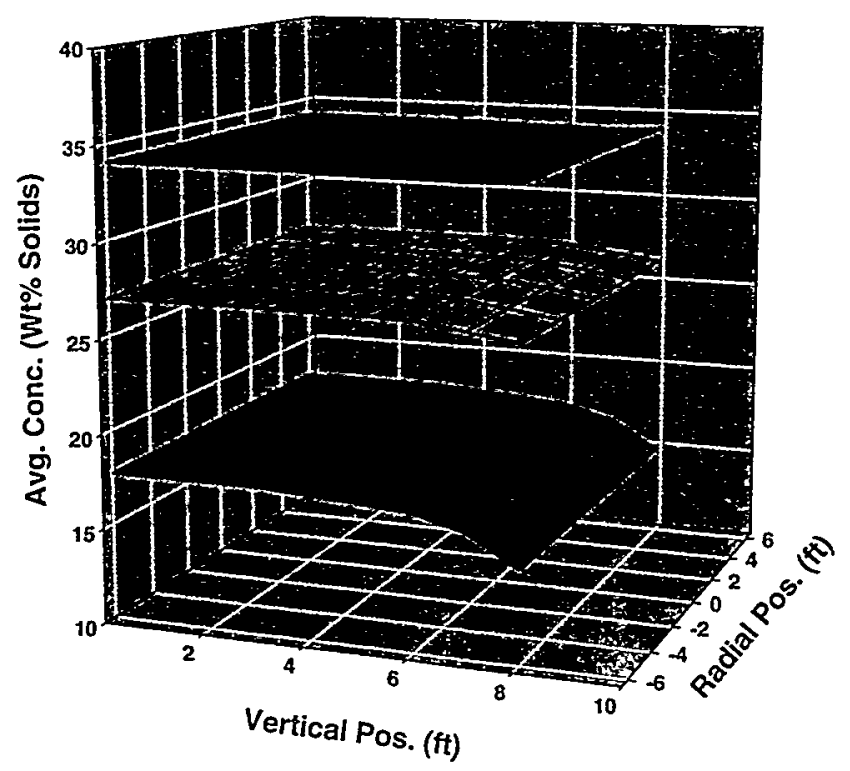

Figure 3.1. Mixer Performance at Different Initial Solids Loading of 17 (Red), 28 (Yellow), and 36-wt\% (Blue) when All Four-Pulse Tubes Are Operated At Maximum Frequency. 
In Figure 3.1, the $x$-axis represents the radial sampler position and the $y$-axis represents the vertical sampler position. It can be seen from Figure 3.1 that at any particular vertical location of the sampler, there is no variation in the concentration profiles within the radial position for three different solids loading. Similar results were observed with all other testing sequences. Also the data in Figure 3.1 indicates that at 28 and $36-w t \%$ initial solids loading, the concentration at all vertical locations within the tank was constant indicating that the contents of the tank were completely homogenized. At the low initial solids concentration, it can be seen from this figure that the solids concentration begins to drop at heights above 6-ft from the bottom of the tank and the homogeneity index at the vertical height of 7 -ft drops to $82 \%$. This indicates that some stratification of the solids does occur at the low solids loading. Examining the rheological and settling rate properties of the slurries in Table 3.1 can shed some light on these results.

The viscosities of the slurries listed in Table 3.1 are low (on the order of a few cP) indicating that, in this study, viscosity was not a significant contributor to the settling characteristics of the slurries. The data in Table 3.1 also indicates that lowering the concentration does have a significant effect on the hindered settling behavior of the solids. Therefore, in the present case, where viscosity effects are minimal, we believe that the mixer performance is rather largely dictated by the settling rates of the solids. At the intermediate and high solids loading, where the solids settling rate is sufficiently low to influence the mixing, we observed the best performance. At the low solids concentration, where settling effects are more predominant, stratification of the solids in the lower part of the tank was observed.

It should be noted that the Pulsed Jet mixer design for the present testing was based on the actual waste settling data of the AZ-101/102 slurries which are significantly lower than the simulants used in this study (see Appendix A). Although increasing the drive pressure of the Pulsed Jet mixers could further increase the mixing energy, this was not done due to the limited time available for the tests.

Table 3.1. Viscosity and Computed Settling Rate Properties of the Three Simulated Slurries Tested in the Assessment of the Pulsed Jet Mixing and RFD Sampling Systems.

\begin{tabular}{cccc}
\hline $\begin{array}{c}\text { Solids } \\
\text { Concentration }\end{array}$ & @ @ Shear Rate of 33 Hz & @ Shear Rate of $300 \mathrm{~Hz}$ & $\begin{array}{c}\text { Settling Rate } \\
\text { (cm/sec) }\end{array}$ \\
\hline & 9 & 1.5 & 9.25 \\
17 & 17.5 & 6.9 & 5.25 \\
36 & 26 & 17.5 & 2 \\
\hline
\end{tabular}

\subsection{TIME TO ACHIEVE HOMOGENEITY}

At the beginning of all tests, the MicroMotion density measurements were made with sample being drawn from the center of the tank a depth of 5-ft from the bottom. After steady state was achieved, the sampler location was varied to determine how the concentration profiles varied within the entire tank. This section discusses some of the trends of the mixing profiles obtained. 
Figure 3.2 shows the variation of the density of the slurry at the sampler location as a function of time for the 17 -wt\% solids loading test with all four operating at maximum frequency. The time averaged $^{1}$ solids-concentration profile for the same tests is shown in Figure 3.3. Also shown in these figures, for comparison purposes are the mixing profiles when only one pulse tube was operating at maximum frequency. The overshoot in the density and the solids concentration in Figures 3.1 and 3.2 above that of the steady state value was due to the fact that the experiments were all started with the solids settled at the bottom of the tank and the MicroMotion sampler tube at the 5-ft height. As the mixing proceeds and the solids get pushed to and above the sampler the location, the concentration increases and then decreases (i.e., as part of and the entire tank was homogenized).

It can be seen from the four pulse tube data Figure 3.2 that a steady state in the density (and solids concentration in Figure 3.3) was achieved within 1-hr of operation. Also, as expected, as the number of pulse tubes operating at a time was reduced there was a concomitant increase in the time required to achieve steady state.

The effect of solids loading on the time to achieve steady state for the four pulse tubes operating at maximum frequency is shown in Figure 3.4 for the three initial solids loading of 17,28, and 36-wt\%. Once again, these results are expected since an increase in the solids concentration will result in an increased time for mixing.

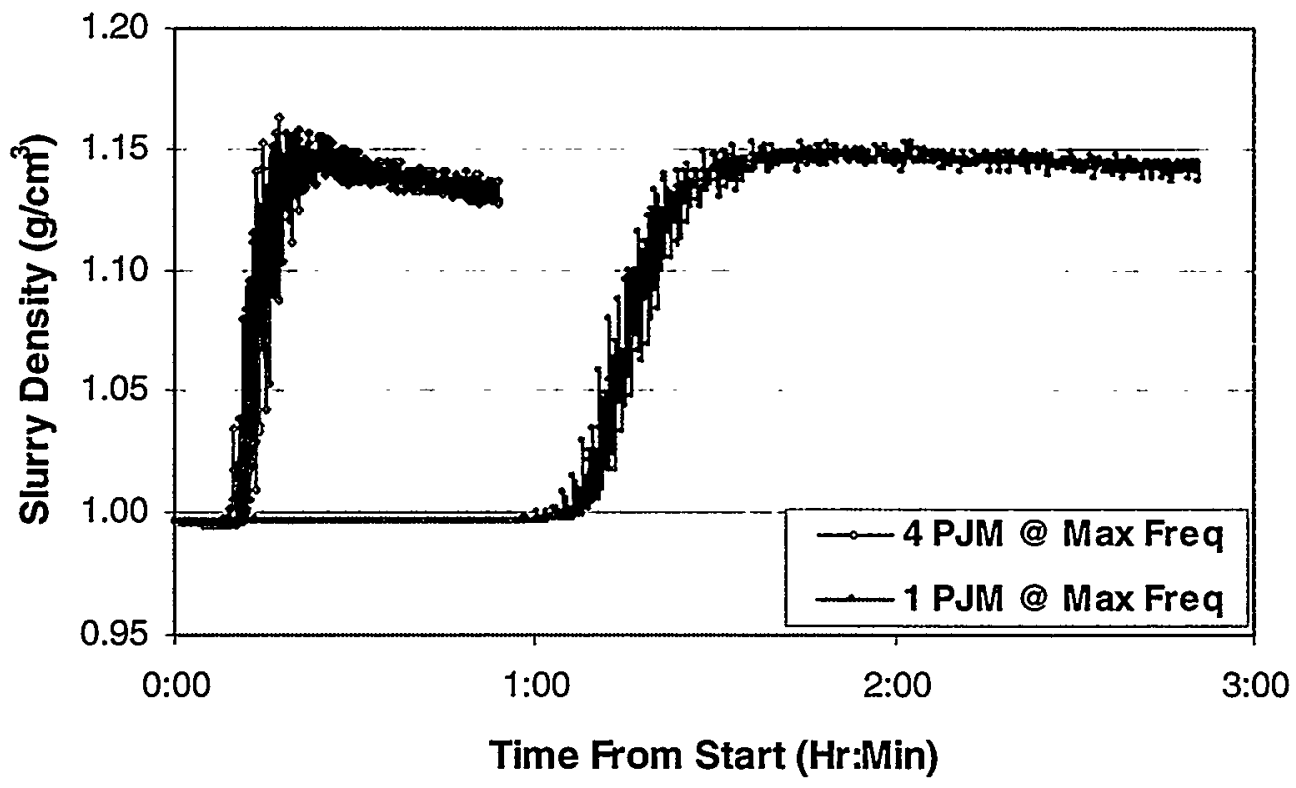

Figure 3.2. Slurry Density Profiles at an Initial Solids Loading of 17-wt\%.

\footnotetext{
' The MicroMotion sampler data was measured at 10 -second intervals and the time averaged data was computed by averaging the densities over five sample points.
} 


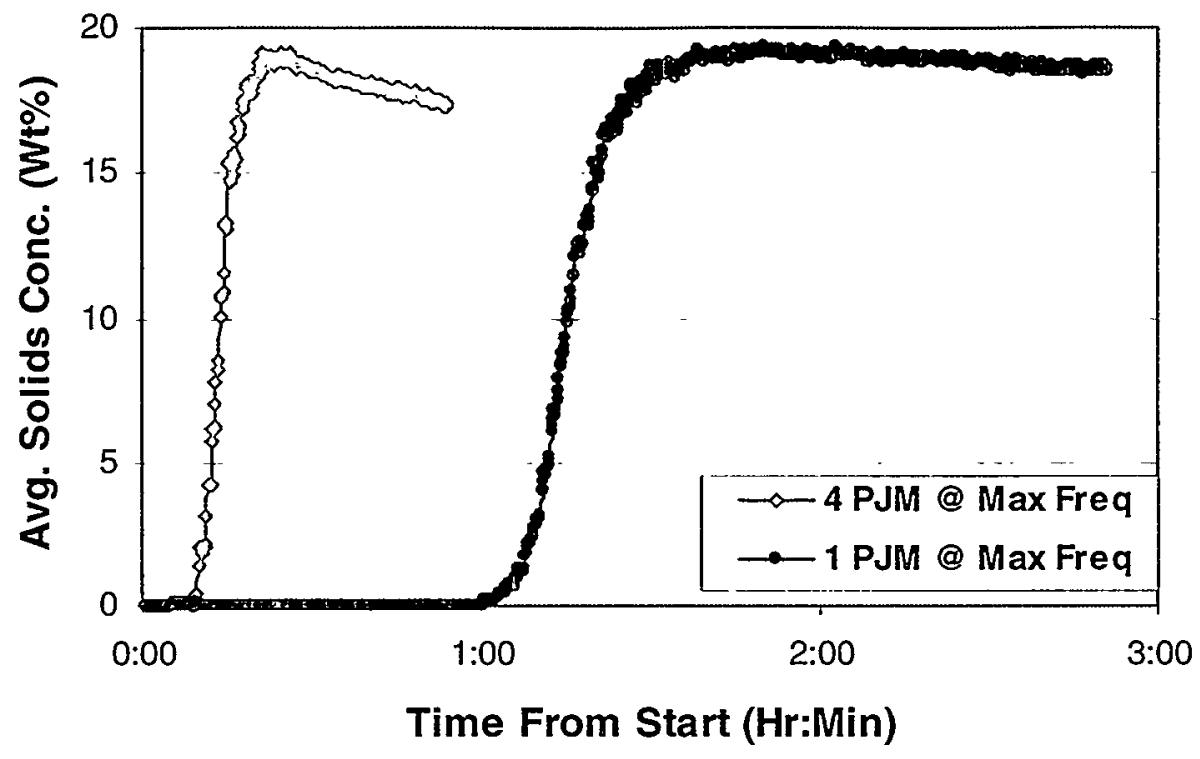

Figure 3.3. Average Solids Concentration Profiles at 17-wt\% Initial Solids Loading.

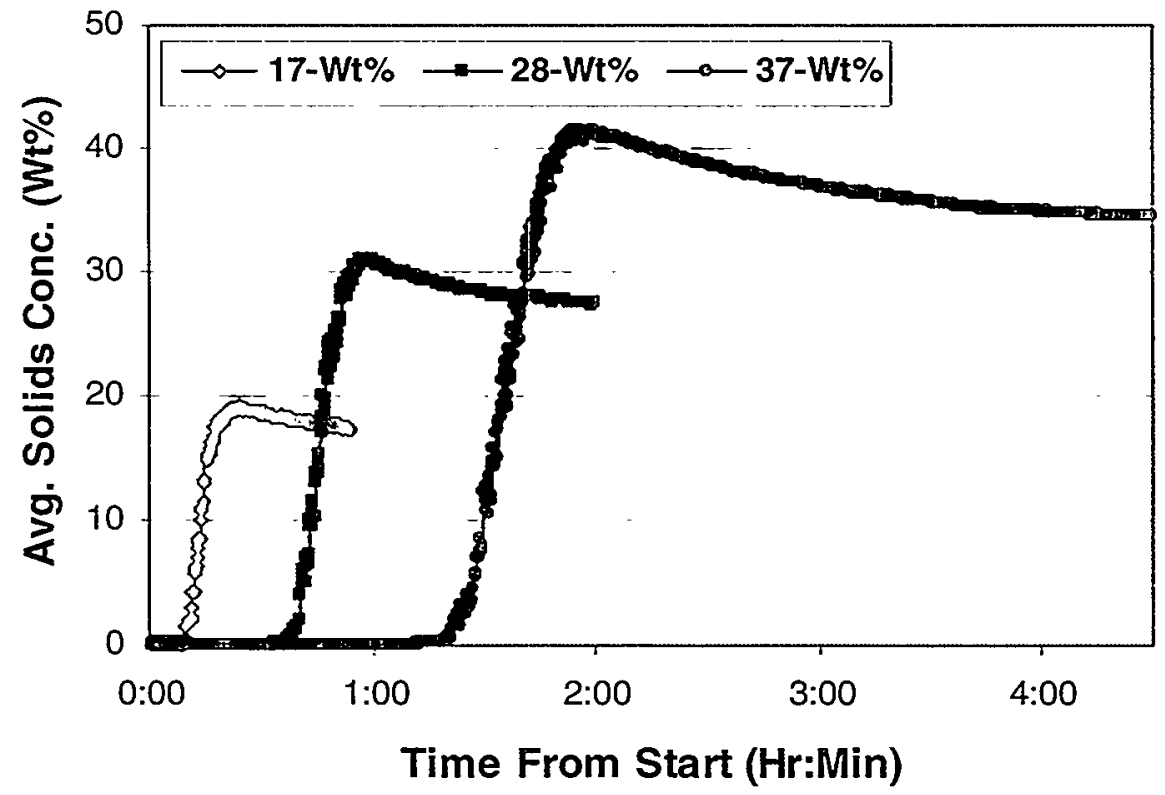

Figure 3.4. Average Solids Concentration Profiles at 17, 28, and 36-wt\% Initial Solids Loading. 


\subsection{RFD PERFORMANCE}

Initially, the density of samples collected from the RFD sample station and occasionally from the RFD return line was determined by a handheld density meter. However, this approach was found to be very unreliable and yielded widely varying density values for the same sample due to unavoidable air entrainment in the sample fed the density meter. This approach was therefore abandoned and the density of the sample from the RFD sample station was determined using a 50-mL density bottle. This approach, although more reliable was still susceptible to errors in transferring thoroughly homogenized slurry to the density bottle. Therefore in assessing the RFD sampler performance, an error of within $5 \%$ of the actual was considered to be within experimental error of measurement.

A comparison of the RFD sample density with that obtained using the MicroMotion meter at the same location are shown in Figure 3. 5. In Figure 3.5, samples 1-3 were collected at 17 -wt $\%$, samples 4-7 at 28-wt\%, and samples 8-9 at 36-wt\% solids loading. It can be seen from the figure, that the RFD sample data compared reasonably well with the MicroMotion data within an experimental error of $5 \%$. However at the very high solids loading, the differences between the RFD sample and MicroMotion data was far more significant indicative of the fact that the sampler was unable to obtain a representative sample of the slurry at such an high concentration.

At 36-wt\% solids loading, a sample was taken from the RFD return line to the tank and this compared very well with the MicroMotion data. Therefore, it was concluded that it was the sample $T$ (rather than the RFD pump) which was unable to deliver a representative sample at the 36-wt\%. Bigger needles can be used with the sampler Tee but these tests were not performed due to time constraints. In addition, the maximum concentration for the RPP baseline is $25-\mathrm{wt} \%$ and there was no pressing need to establish the RFD performance at the $36-w t \%$.

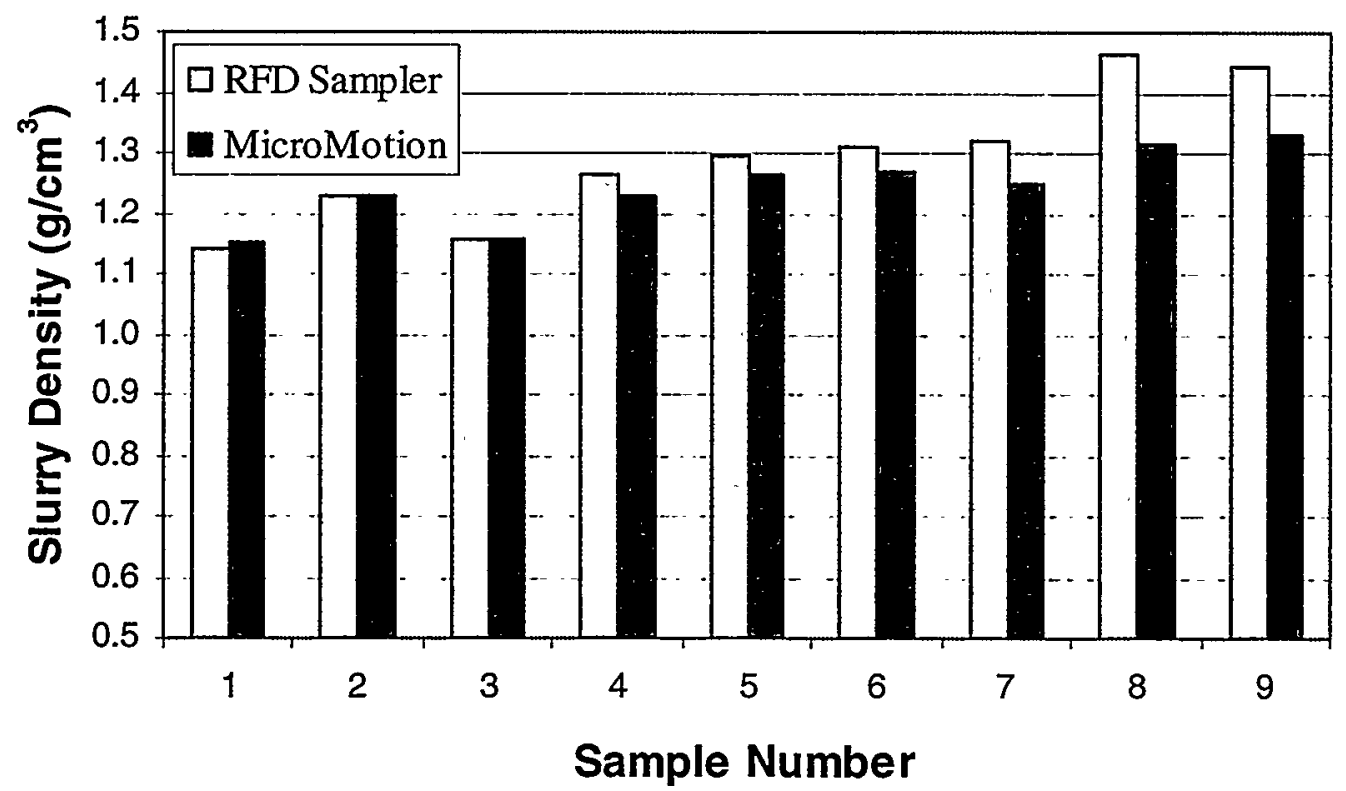

Figure 3.5. Comparison of RFD Sample Density with that Obtained from the MicroMotion Density Meter Sample Drawn at the Same Location. 
The RFD performance was not entirely trouble free. The RFD became plugged during a few occasions. There are two reasons for this: (1) solids were allowed to settle and compact between tests and (2) the RFD was not pulsed when not in use. In the actual plant solids would not be allowed to settle and RFD's in arduous duties would be continuously pulsed to prevent solids from settling in the lines. vessel.

Unplugging the RFD was not a major problem and was achieved by rapid pulsing of the charge

The unplugging of the sample needle, however, proved to be more difficult and required dismantling the assembly. However, in the actual plant design this is not considered a major issue since this is generally accomplished by automatic sampler cleaning and changing equipment, which are part of the BNFL's autosampler design.

\subsection{KEEPING SOLIDS SUSPENDED AT MINIMIZED AIR INPUT}

To evaluate whether a thoroughly homogenized or mixed slurry could be kept suspended at reduced air input to the Pulsed Jet mixers, the system was tested at different operating sequences and frequencies at the three initial solids loadings of 17,28 , and $36-w t \%$. In all these experiments, the slurry was initially homogenized with all four pulse-tubes operating at maximum frequency before changing the frequency or sequence of operation of the pulse tubes.

\subsubsection{7-Wt\% Initial Solids Loading}

As mentioned in the experimental section, the most extensively tested system was the initial 17 -wt\% solids loading. The results of the tests for the various operating conditions tested are presented in Figures 3.6a to 3.6d. In general, it can be seen from Figures 3.6a to 3.6d that the concentration profiles in the tank are dramatically changed as the number of pulse tube and/or the frequency of operation was reduced.

Even when the pulse tubes are operating at maximum frequency (cf. Figure 3.6a), a reduction in the number of pulse tubes operating at a time results in significant stratification in the solids in the lower half of the tank. This effect becomes more pronounced when, in addition to reducing the number of pulse tube, the frequency of operation is also reduced as can be seen from Figures $3.6 \mathrm{~b}$ to $3.6 \mathrm{~d}$. 
(a)
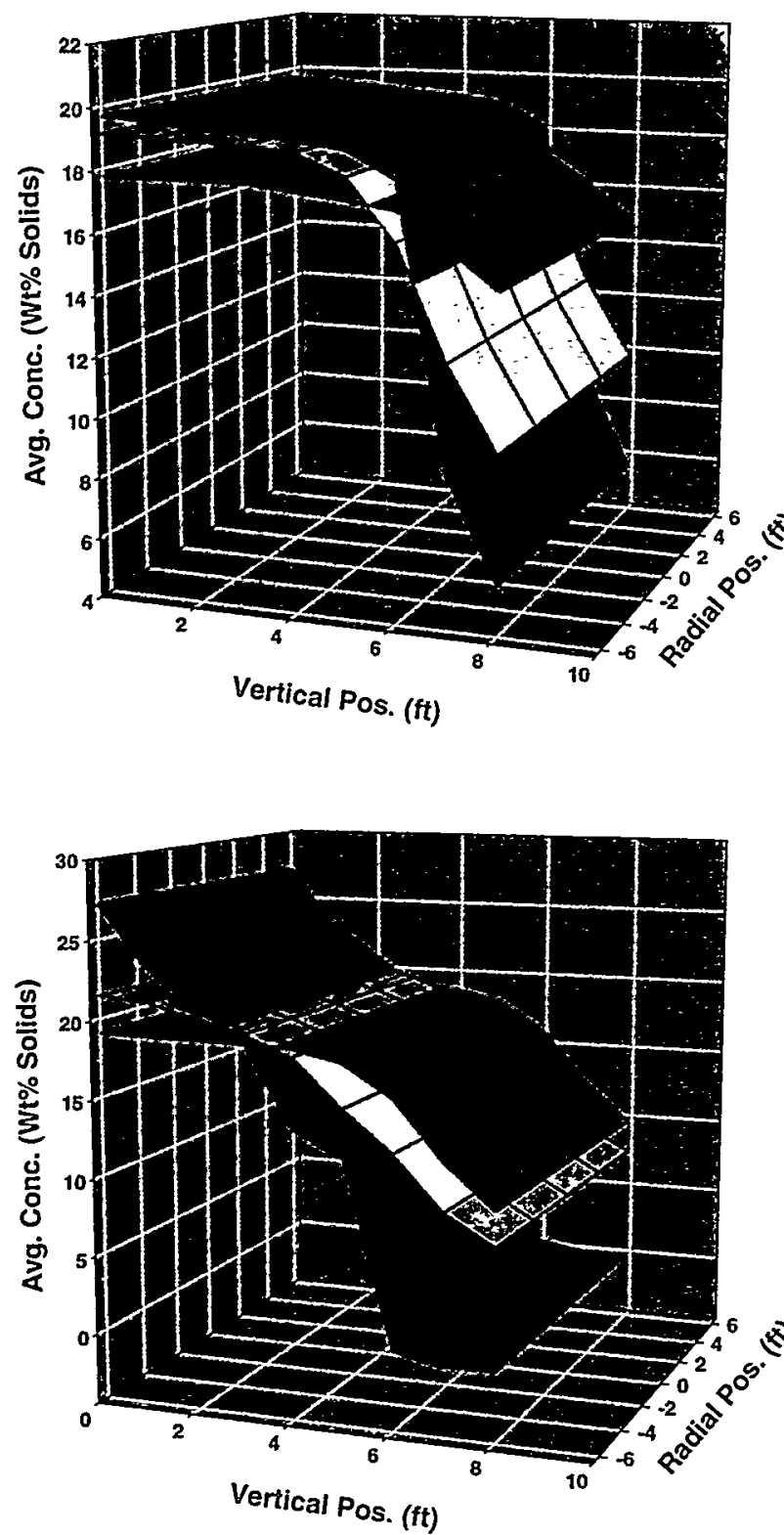

(c) (b)
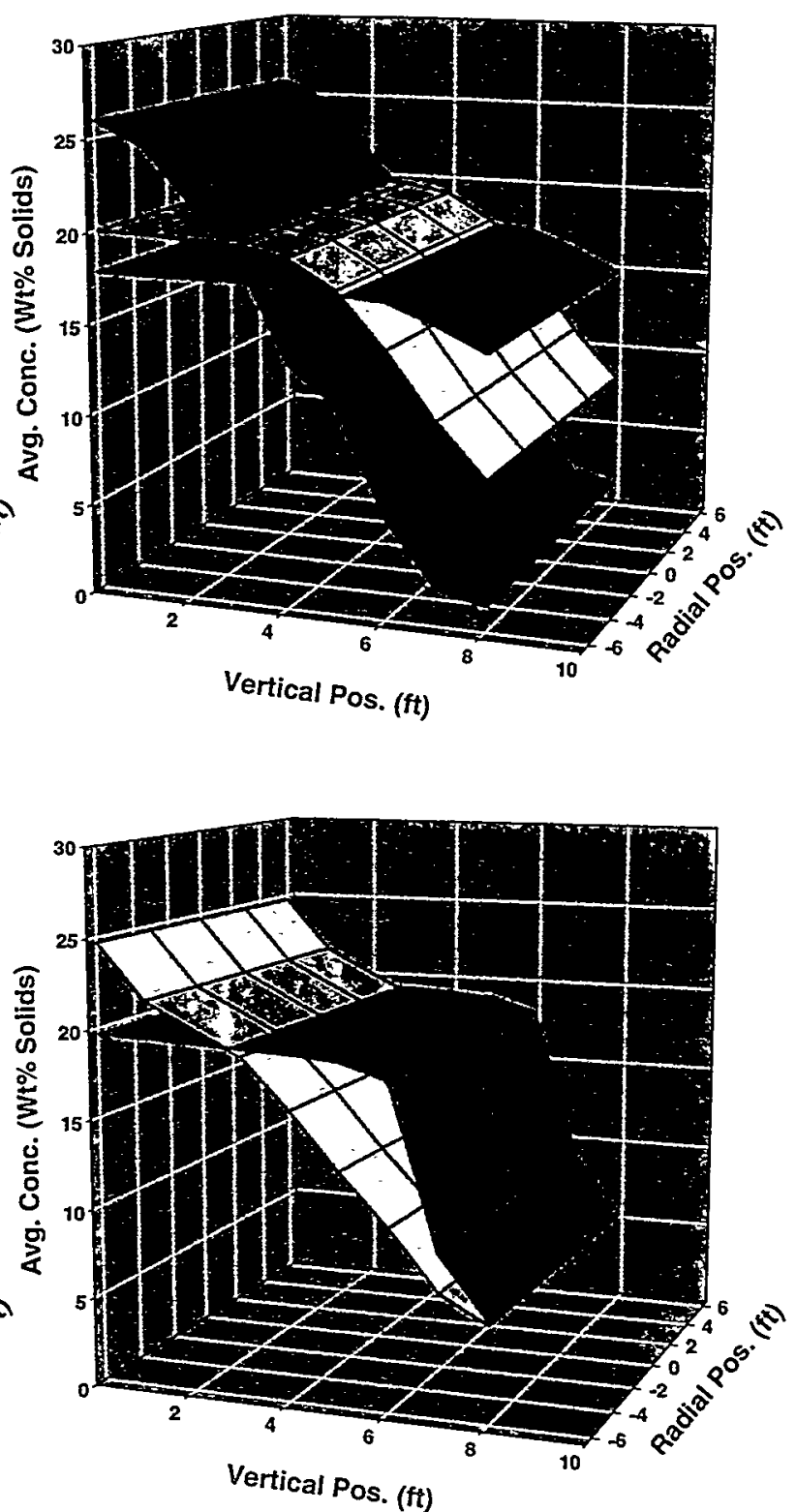

(d)

Figure 3.6. Mixing Profiles at $17-w t \%$ Initial Solids Loading. (a) Four (Red) and Two (Yellow) PJM Operating at Maximum Frequency of Operation. (b) Four PJM's Operating at 100 (Red), 50 (Yellow), and 10\% (Blue) of Maximum Frequency. (c) Two PJM's Operating at 100 (Red), 50 (Yellow), and 10\% (Blue) of Maximum Frequency. (d) One PJM Operating at 100 (Red), and 50\% (Yellow) of Maximum Frequency. 


\subsubsection{8-Wt\% Initial Solids Loading}

The results of the tests at $28-w t \%$ initial solids loading and various operating conditions tested are presented in Figures 3.7a to 3.7c. Once again, it can be seen from all these figures that the performance of the Pulsed Jet mixing system deteriorates as the number of pulse tube and/or the frequency of operation was reduced. Although as in the case of the $17-w t \%$ initial solids loading tests, stratification of the solids was also observed, it can be seen that in the present case, the drop in the concentrations was more abrupt as opposed to a much more smoother decline in the solids concentration as we move to the top of the tank. This is due to the slower settling rates discussed previously and therefore in regions of the tank where the mixers were effective, the solids concentration remained more constant.

\subsection{3 $36-\mathrm{Wt} \%$ Solids Loading}

The results of the few tests conducted at the 36-wt\% solids loading are shown in Figure 3.8. It can be seen here that despite changing the operating frequency or the number of pulse tubes operating at a time, the profiles for all the three tests are almost identical and the tank was thoroughly homogenized. As discussed earlier, this is due to the fact that settling rates effects which dominated the mixing processes in the $17-\mathrm{wt} \%$ and to some extent in the $28-\mathrm{wt} \%$ concentration range are completely negligible and the slurry remains completely suspended after homogenizing with four pulse tubes and then reducing the air usage by $50 \%$ by either reducing the number of pulse tubes operating at a time to two or decreasing the frequency of operation by $50 \%$. Although these results indicate that $50 \%$ reduction in the air usage is possible under the present scenario whether it is unclear at the present time whether a further reduction in air usage is possible and whether the slurry can be homogenized when the mixing is initiated with just two or one pulse tube operating at maximum frequency. These tests were not conducted due to limitations in the time for the experiments. Also it is unclear at the present time as to the effect a further increase in the slurry viscosity will have on the mixer performance. 
(a)

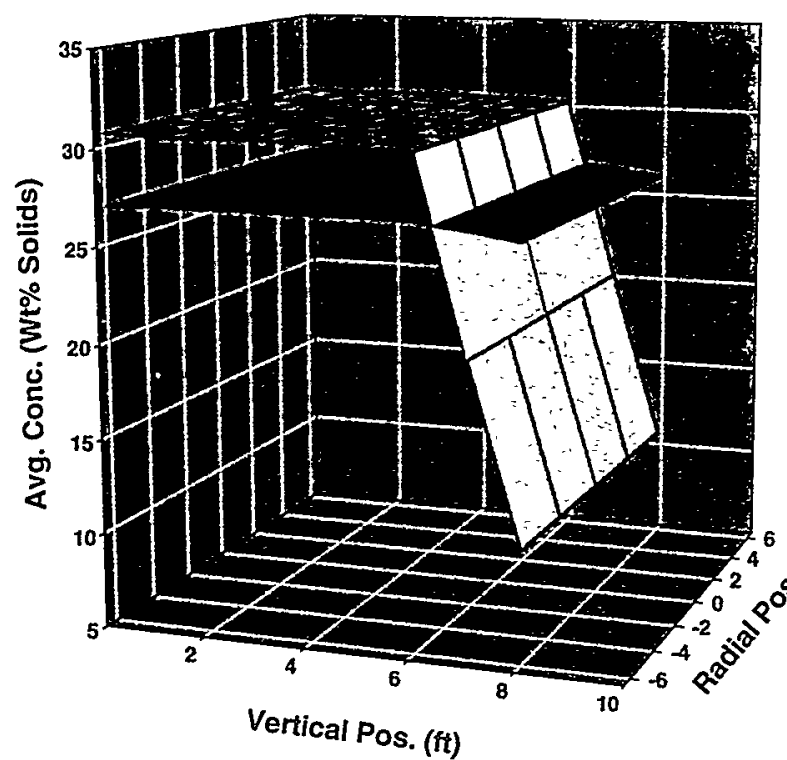

(c)

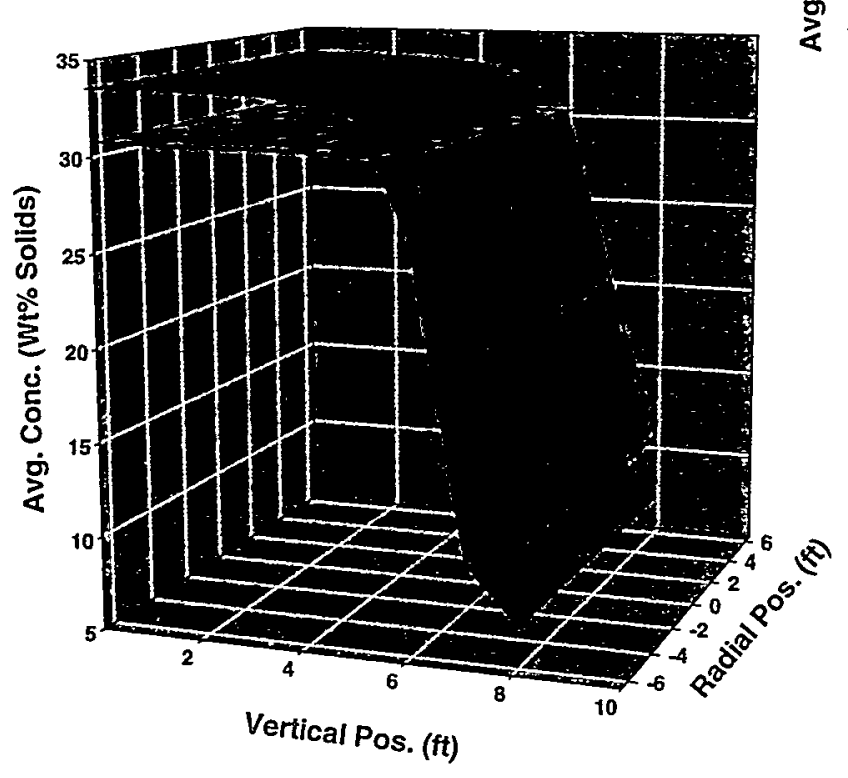

(b)

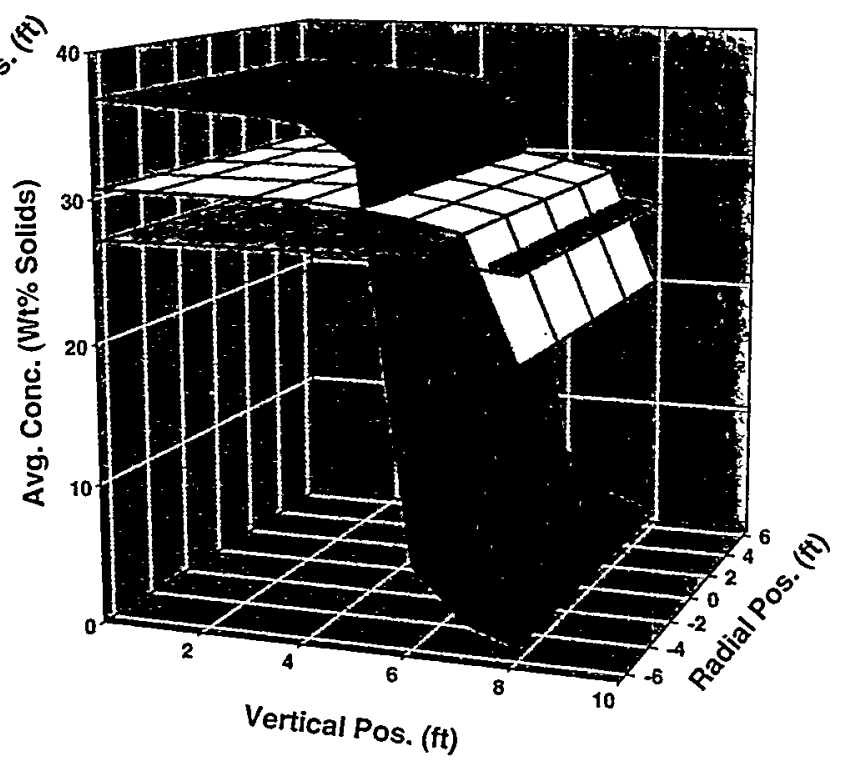

Figure 3.7. Mixing Profiles at 28-wt\% Initial Solids Loading. (a) Four (Red), and two (Yellow) PJM Operating at Maximum Frequency of Operation. (b) Four PJM's Operating at 100 (Red), 50 (Yellow), and 10\% (Blue) of Maximum Frequency. (c) Two PJM's Operating at 100 (Red), 50 (blue) of Maximum Frequency. 


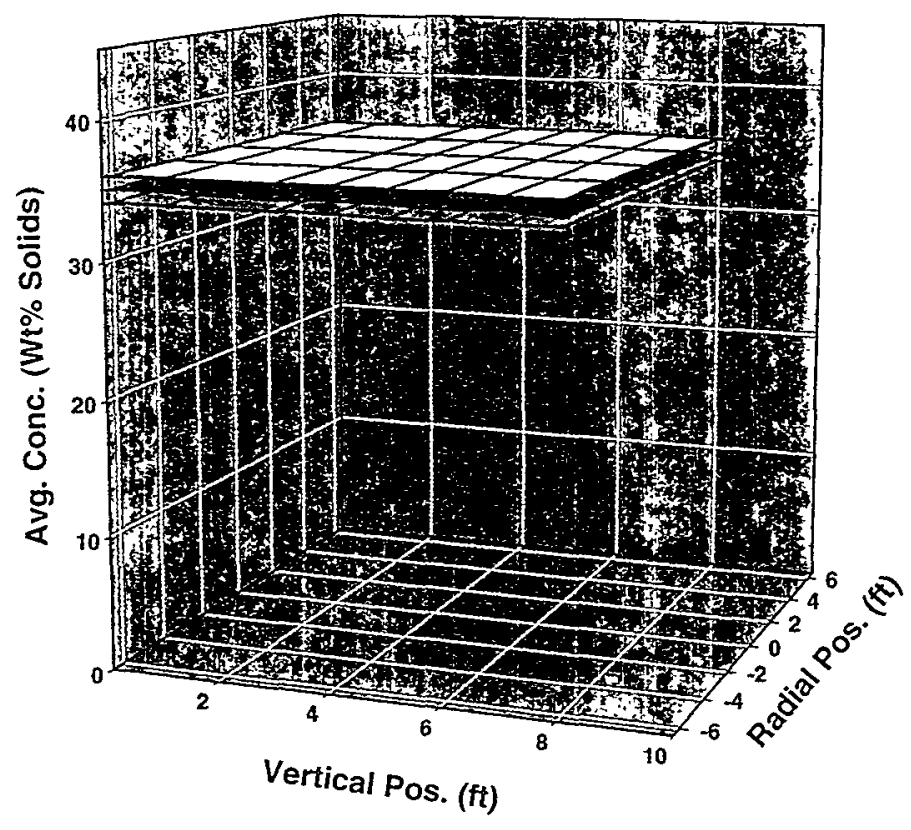

Figure 3.8. Mixing Profiles for 36-Wt\% Initial Solids Loading. Curves in Red and Yellow are for 4 and 1 PJM Operated at Maximum Frequency. Blue Curve Represents the Data for 4 PJM at 50\% Frequency.

\subsection{IMPACT OF RESULTS ON PLANT DESIGN AND OPERATION}

\subsubsection{Mixing of Tanks}

The day-to-day operational requirement for RPP-WTP tank mixing is to keep the solids off the bottom of the tank. This prevents settling, agglomeration and the possibility of a gas release event (GRE).

This work has confirmed that when all pulse jet mixers within a tank are operating at the design frequency and pressure, then the tank can be homogenized. By operating the pulse jet mixers sequentially at the design frequency or at half the frequency, acceptable mixing can be obtained to keep the solids suspended.

The only time a tank needs to be homogenized is to provide a representative sample or possible during a transfer operation.

It has been shown that a tank containing 28 - wt\% slurry can be homogenized from fully settled in just 1-2 hours. As the concentration of slurry is reduced, the time to homogenize tank contents is significantly reduced.

It is recommended that a study be carried out with dynamic modeling, to link tank utilization and sampling requirements with air usage and vent flowrate during pulse jet mixer and RFD operation. This would allow sizing of both the compressor and vent systems to cope with peaks and troughs in air demand and this in turn can be related to the vent system requirements. 


\subsubsection{Vent System}

The RPP-WTP RFD and Pulsed Jet mixer vent design incorporates HEPA filters and HEMEs. If the air usage for the pulse jet mixers is reduced by $80 \%$ then significant size reductions and savings can be made to the vent systems in Pretreatment, LPP and HLW Vitrification. The number of HEPAs and HEMEs can be reduced as well as fan requirements and associated equipment. The calculated air consumptions for the pulse jet mixers are shown in Table 3.2.

Table 3.2. Air Consumptions Requirements for Pulse Jet Mixers

\begin{tabular}{lcc}
\hline System & \multicolumn{2}{c}{ Air Usage (SCFM) } \\
\cline { 2 - 3 } & PJM Operated & $\begin{array}{c}\text { PJM Operated } \\
\text { Sequentially }\end{array}$ \\
\hline Simultaneously & 38,000 & 8,700 \\
Pretreatment & 7,200 & 1,500 \\
HLP & Calculations not available but & Calculations not available but \\
& similar to LPP & similar to LPP \\
& & \\
\hline
\end{tabular}

There is scope for further reducing the air requirements by operating pulse tubes sequentially at less than design frequency. Current figures assume design frequency. If the pulse jet mixer air usage requirements are reduced by $80 \%$ to keep the particles suspended, then the sizing of the RPP-WTP compressor needs to be revisited.

\subsubsection{Wash Down of Pulse Jet Mixers, RFD Airlines and Charge Vessels}

During operation of the mixers and RFD, the airlines became coated with the simulant to the height of the suction of the liquid. Over a number of weeks, a thin coating of simulant worked its way up to the top of the air-link pipe and began moving slowly towards the jet pump pairs, as shown in Figure 3.9.

This is a well-known phenomenon that occurs with shear thinning materials such as the ferric hydroxide floc that BNFL uses in the Enhanced Actinide Removal Plant at Sellafield.

Wash down facilities are normally installed to clean the lines on a regular basis. The wash down facilities may take a number of forms and can either be done from the bottom up or the top down. By following operational procedures, BNFL has not has a problem with ferric hydroxide floc in the vent lines.

A consideration for future work may be to mock up the system with hard piping and wash down facilities and test it with the simulant. Although with BNFL's experience of the operation of wash down systems with ferric floc, this is thought unnecessary. 

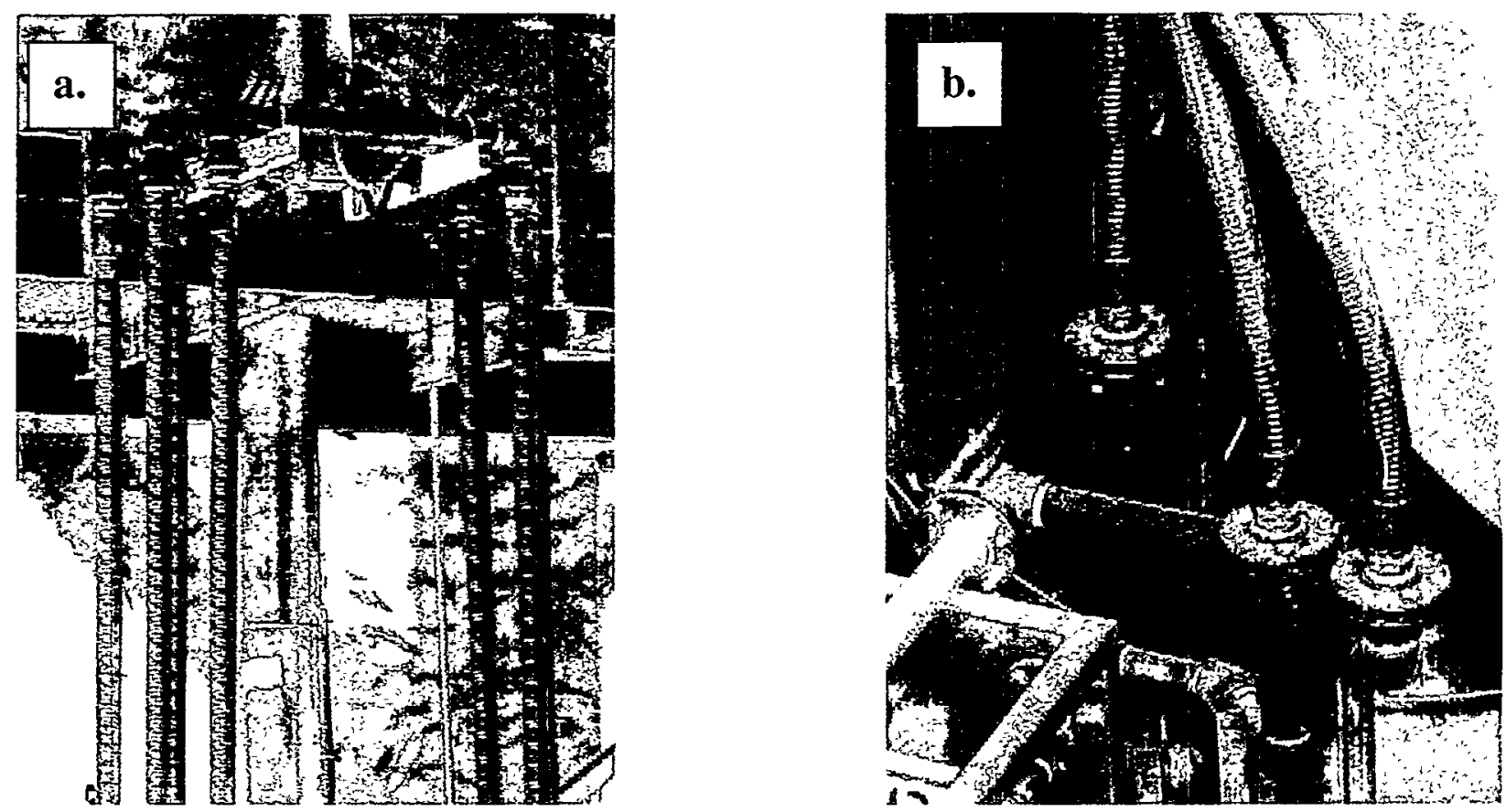

Figure 3.9. Photographs of the Air/Vacuum Lines Showing Slurry Coating at (a) Top of the Upper Cat Walk and (b) Control Module.

\subsubsection{Automatic Sampler T}

During the trials, the RFD was left pumping for long periods of time and the sample T needle became blocked. The test conducted was to demonstrate of the ability of and RFD to pump and sample the slurry, not a demonstration of the auto sampler system. BNFL has designed an automatic sampler system that allows for automatic replacement of the needle and cleaning of the sample $T$.

\subsubsection{Operation of RFDs}

A couple of times during the trials it was difficult starting the RFD due to blockages in the lines. The blockages were caused by a high concentration of solids being allowed to settle and compact overnight.

The RFDs were started by carrying out a line clearance cycle which is standard practice. Mechanical means were not needed to remove the blockage. If this has been a mechanical pump, it is unlikely that the solids would have been shifted. RFDs operating in such an environment would normally be pulsed back and forth when not pumping to prevent solids settling in lines. 


\subsection{CONCLUSIONS AND RECOMMENDATIONS}

- In all, the performance tests on the BNFL's Pulsed Jet mixing and RFD sampling system indicate that these systems are capable of handling slurries of high solids loading. The absence of any moving parts makes these systems extremely attractive to handle highly radioactive wastes.

- $\quad$ At the present design, the Pulsed Jet mixing system with all four-pulse tubes operating at maximum frequency thoroughly homogenized the intermediate and high solids loading cases for the AZ-101/102 simulant studied.

- With fast settling slurries, such as case with the $17-w t \%$ initial solids loading tests, the results indicate that even with all four pulse tubes operating at maximum frequency some stratification does occur. However, this is due to the fact that the BNFL's design of the Pulsed Jet mixing system was based on the slower settling AZ-101/102 actual waste data.

- $\quad$ Reducing the air requirement by $80 \%$ or more are possible if the goal is to suspend the particles after the mixers operating at maximum efficiency homogenize the slurries.

- Optimizing the air usage by either decreasing the number of pulse tubes operating and/or pulse frequency generally resulted in deteriorating mixer performance except at the very high solids loading of 36-wt\%. However, this scenario was not completely studied to completely assess the air usage on the mixer performance.

- For the cases studied, viscosity of the slurry did not effect the mixer performance. Furthermore, BNFL plants routinely handle slurries of viscosities of up to 7-poise.

- The RFD sampler, within experimental error, was effective in taking a representative sample of the slurry at the low and intermediate solids loading.

- The RFD sampler did not take a representative sample of the slurry at the very high solids loading of 36-wt\%. This was, however, attributed to the use of the smaller diameter needle rather than the RFD pump itself.

- $\quad$ RFD charge vessel and sampler plugged several times during their operation.

- Unplugging the RFD charge vessel was relatively easy and required rapid pulsing of the slurry through the charge vessel.

- Unplugging the RFD sampler was difficult and required dismantling the assembly to remove the slurry dislodged in the sampler. However, in actual plant operations, BNFL's auto sampler is designed to overcome these problems.

- Slurry transfer into the down leg of the air/vacuum lines was observed. This phenomenon is very common with shear thinning slurries. BNFL addresses this issue in their plants by incorporating wash down facilities to clean the air/vacuum lines.

Based on these results, the following are some of the recommendations for future work in this

area:

- Evaluate the mixer performance especially at the low solids loading where the settling rates are very high.

- $\quad$ Develop Computational Fluid Dynamic (CFD) models to predict the mixer performance especially in very large tanks containing several pulsed-jet mixers.

- $\quad$ Evaluate the influence of tank internals on the mixer performance. 


\subsection{REFERENCES}

Barnes, H. A., J. F. Hutton, and K. Walters. 1993. An Introduction to Rheology, Elsevier Sciences Publishers, Amsterdam, The Netherlands.

Gray, W. M. E. Peterson, R. D. Steele, and T. M. Tingy. 1990. Characterization of the First Core Sample of The Neutralized Current Acid Waste from Double Shell Tank 101-AZ, PNNL-11103, Pacific Northwest National Laboratory, Richland, Washington.

Gray, W. M. E. Peterson, R. D. Steele, and T. M. Tingy. 1993. Characterization of the First Core Sample of The Neutralized Current Acid Waste from Double Shell Tank 102-AZ, PNNL-13026, Pacific Northwest National Laboratory, Richland, Washington.

Golcar, G. R., K. P. Brooks, J. G. Darab, J. M. Davis, L. K. Jagoda. 2000. Development of Inactive High-Level Waste Envelope D Simulants for Scaled Crossflow Filtration Tests, PNWD-3042, Battelle, Pacific Northwest Division, Richland, Washington. 


\section{APPENDIX A}




\section{APPENDIX A: SIMULANT PROPERTY VERIFICATION}

For the testing of the Pulsed-Jet mixing system and RFD sampling systems, BNFL has identified the NCAW slurries to be indicative of some of the worst-case scenario conditions encountered during the Hanford waste processing. In this regard, BNFL planned to test the Pulsed Jet mixing and RFD sampling systems using Hanford Tanks AZ-102/102 simulant developed by PNNL for the Crossflow Ultrafiltration (CUF) equipment tests (Golcar et al., 2000). In addition, in order to simulate the washed solids, BNFL indicated that the aqueous phase of the simulant be water at pH 12 (i.e. $0.01 \mathrm{M} \mathrm{NaOH}$ ).

The AZ101/102 simulant consists of an aqueous phase with $0.8 \mathrm{M} \mathrm{NaNO}_{3}$ and $1.0 \mathrm{M} \mathrm{NaOH}$. Although this simulant has been well characterized and its physical and rheological properties documented, changing the supernate phase to $\mathrm{pH} 12$ with no sodium nitrate could alter the properties of the simulant. Therefore, the scope of this task was to measure the physical and rheological properties of the AZ-101/102 simulant at $\mathrm{pH} 12$ with no dissolved $\mathrm{NaNO}_{3}$ and to compare these properties with the CUF simulant and actual AZ-101/102 waste. In addition, since the Pulsed jet mixer performance depends upon the settling velocities, small-scale settling rate measurements were also conducted. The approach used to measure the slurry physical/rheological properties and the comparison of the results with the CUF simulant and the actual waste are presented in this section.

\section{Rheology of the Pulsed Jet Simulant}

The rheological properties of the Pulsed Jet simulant at different solids loading were determined using a Haake (Model CV 20) rotational viscometer with a concentric cylinder assembly (Model ME45). The advantages of the ME45 concentric cylinder geometry is that it is very suitable for medium viscous slurries and can replicate steady state shear flow conditions $(0$ to $300 \mathrm{~Hz})$. Rheograms of the slurries at ambient conditions $\left(25^{\circ} \mathrm{C}\right)$ were determined under both increasing and decreasing shear rate conditions in the range of 0 to $300 \mathrm{~Hz}$. The reason for confining our measurements to this shear rate range is due to the fact in that typical mixing and stirring processes; the shear rates are between 10 to $1000 \mathrm{~Hz}$ [Barnes 1993].

Figure Al shows the comparison of the measured viscosity versus shear rate data for the pulsed jet mixer simulant with that of the CUF (Golcar et al. 2000) and the actual AZ-101/102 waste (Gray et al. 1990 and 1993) at three different solids loadings of 10, 30, and 40-wt\%. Since the Rheograms of the actual waste samples was not available, the data in Figure A1 was plotted from the viscosity v. shear rate correlations provided by Gray et al. (1990 and 1993).

The data in Figure A1 indicate that the viscosity of the Pulsed Jet simulant at all solids loadings drops to less than $40 \mathrm{mPa}$.s (or $40-\mathrm{cP}$ ) as the shear rate increases from 0 to $300 \mathrm{~Hz}$, indicating a common shear thinning behavior that was also observed with the CUF simulant and the actual waste slurries. Also, the results in this figure indicate that except at very low shear rates, the behavior of the pulsed jet simulant and the CUF simulant are identical indicating that changing the ionic strength of the supernatant does not alter the rheology of the slurries. Finally from Figure A1 it can be seen that the match between the simulant and actual waste slurries is very good given the fact that these simulants were developed to replicate the particle size distribution rather than the rheology. Although some differences do exist between the simulant and the actual waste viscosity properties, the data in Figure A1 indicates that the three solids loading tested in the pulsed jet mixing system evaluation encompass entire viscosity range of the real waste. 

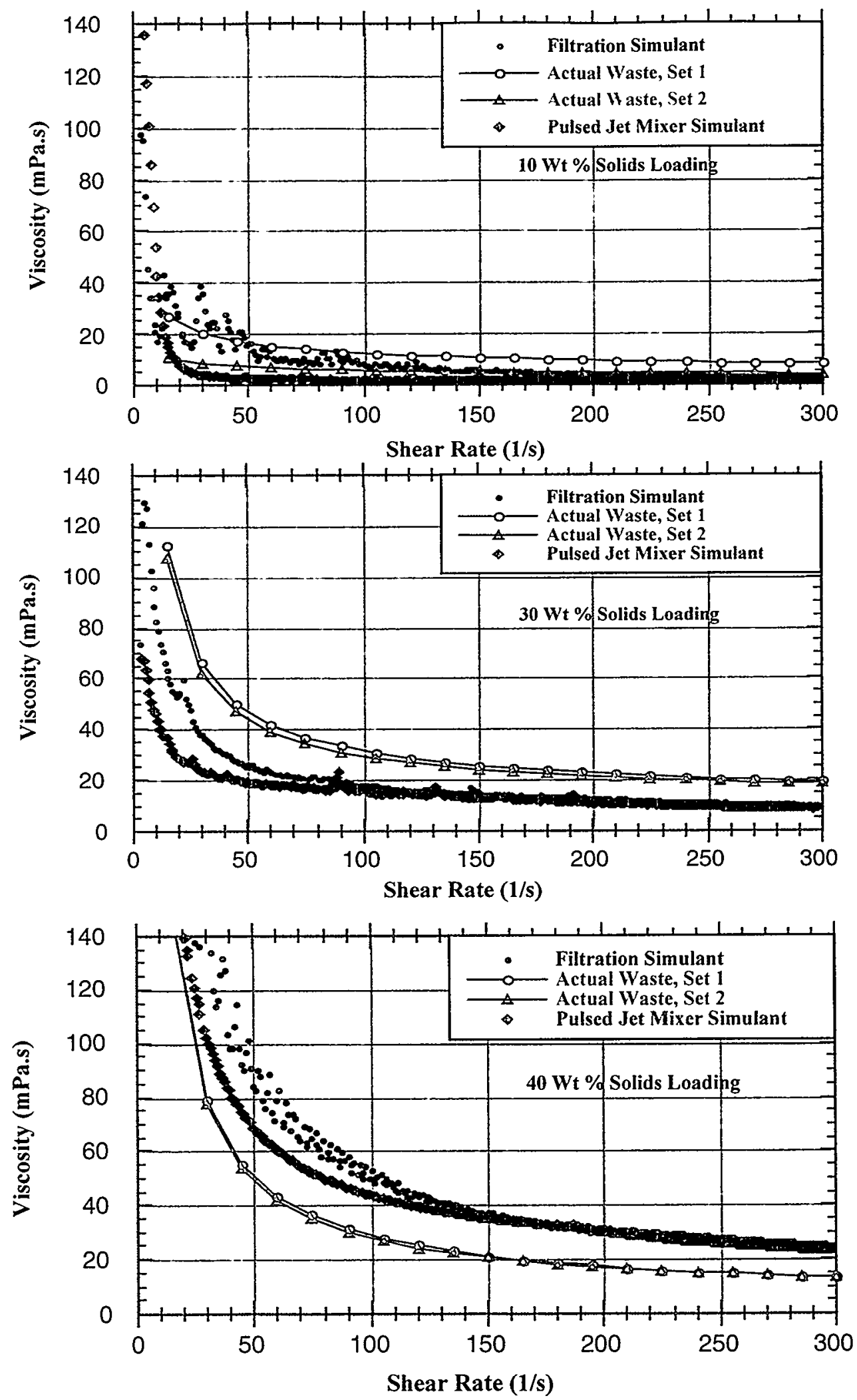

Figure A.1. Comparison of the Viscosity v. Shear Rate behavior for the Pulsed Jet and CUF Simulants with that of the Actual Waste. 


\section{Settling Rate Properties of the Pulsed Jet Simulant}

The settling rate properties of the pulsed jet simulant at different solids loading were determined by carefully recording the change in the height of the clear interface of the supernatant as a function of time. Figure A2 shows a comparison of the settling rate data for the Pulsed Jet simulant with the CUF simulant and the actual AZ-101/102 waste at three different solids loadings of 10,30 , and $40-\mathrm{wt} \%$.

In Figure A2, in order to directly compare the settling rate information with that of the actual waste slurries, the heights of the clear interface were normalized for both the Pulsed Jet and CUF simulant to the height of the samples taken in the actual waste settling data measurement (Gray et al., 1990 and 1993). The following relationship was used to calculate the normalized heights $\left(\mathrm{H}_{n}\right)$ from the height of the slurry at the start of the test $\left(\mathrm{H}_{\mathrm{i}}\right)$, measured time dependent height of the clear interface $(\mathrm{H})$, and the height of the tests in the actual waste settling rate measurement $\left(\mathrm{H}_{\mathrm{a}}\right)$ :

$$
H_{n}(t)=H(t)-H_{i}+H_{a}
$$

For the case of the 10-wt\% solids loading measurement with the pulsed jet simulant, although settled solids were observed, a clear interface was not present. Also, since the CUF simulant in the 10wt\% case compacted more than the actual waste, this resulted in a negative normalized height in Figure A2.

It can be seen from this figure that the settling rate data for the pulsed jet simulant was identical to that of the CUF simulant once again indicating that change in the ionic strength does not significantly influence the settling behavior. Also, in all cases, both the Pulsed Jet and the CUF simulants settle faster than the actual waste streams. This is, however, not detrimental to the tests since settling is a key factor in the mixer performance and the fast settling nature of the simulant actually extends the range of validity of the pulsed jet mixer tests. 

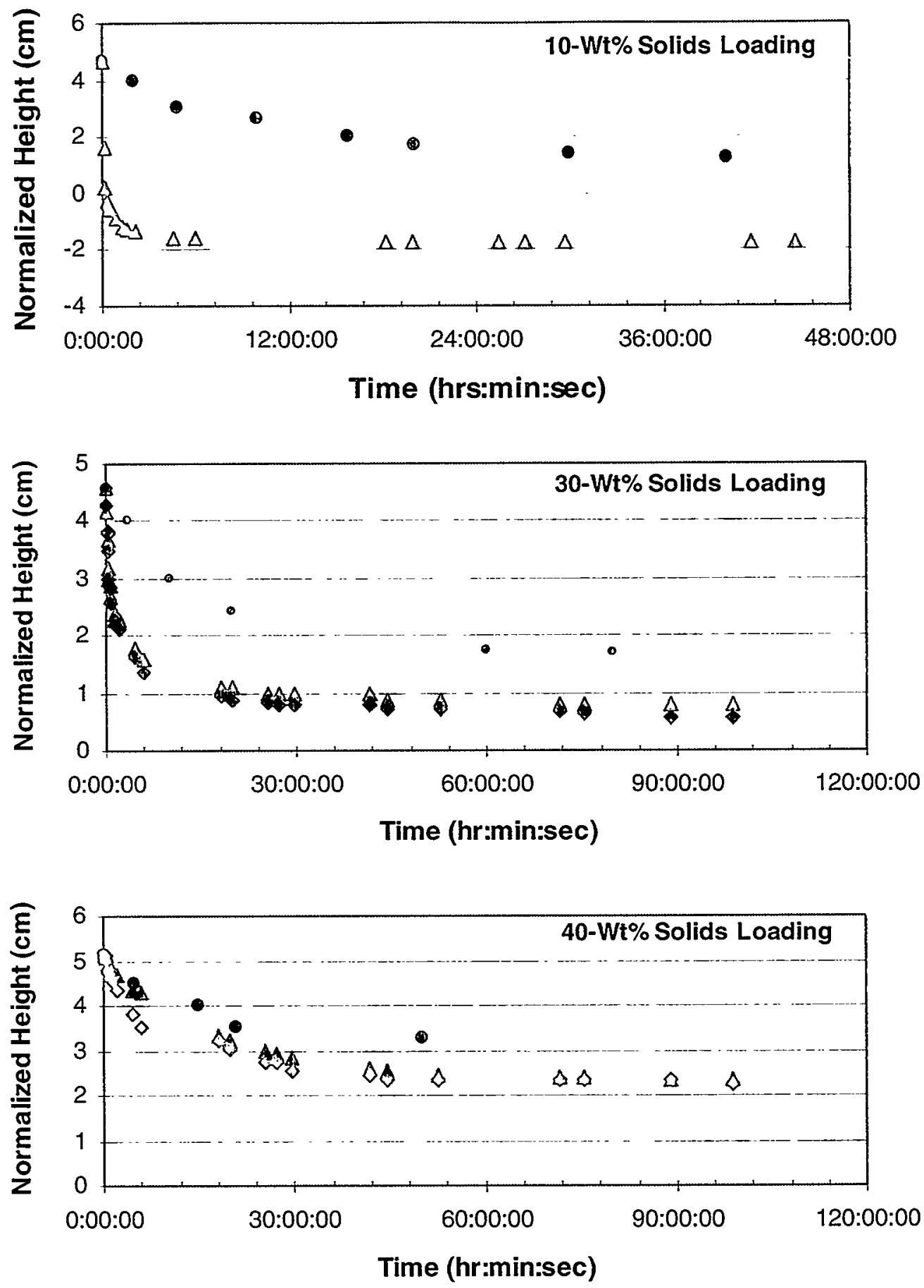

Figure A.2. Comparison of the Settling Rate Behavior of the Pulsed Jet Simulant (in green) with that of the CUF Simulant (in Red) and the Actual Waste (in Blue). 


\section{APPENDIX B}




\section{APPENDIX B: MICROMOTION FUNCTION CHECK}

Prior to the start of the Pulsed Jet mixer and RFD sampler performance testing, a function test on the MicroMotion density meter was performed using DI water, and three standard solutions of sugar water. The three standard solutions were prepared by combining known quantities of sugar and water to yield $\sim 20,40$, and 60-wt\% sugar solutions and stirring the samples for $24 \mathrm{hrs}$ to completely dissolve the sugar. The density of the standard solutions was measured in the laboratory at $20^{\circ} \mathrm{C}$ using density bottles that were calibrated at the same temperature by the manufacturer (ACE Glass Inc.).

The density of the standard sugar solutions was measured using the MicroMotion meter and a comparison of the results is shown in Table B.1. Although some of the later Pulsed Jet mixer and RFD sampler tests were carried out at much higher densities, a standard check was not performed at these high concentrations due to the precipitation of the sugar in the standards at higher than 60 -wt\% concentration. For the four standards used, the MicroMotion measurement was within $0.02 \%$ of the actual indicating that no further calibration was necessary.

Table B.1. Comparison of the Laboratory Sample Density with that measured by the MicroMotion Density Meter.

\begin{tabular}{lcccc}
\hline Standard & Density & \multicolumn{2}{c}{ MicroMotion Readout } & Error (\%) \\
\cline { 3 - 4 } & & Density $\left(\mathbf{g} / \mathbf{c m}^{\mathbf{3}}\right)$ & $\mathbf{T}\left({ }^{\circ} \mathbf{C}\right)$ & \\
\hline DI Water & 0.9978 & 0.9977 & 21 & 0.01 \\
20\% Sugar Sol. & 1.0837 & 1.0851 & 21 & -0.12 \\
40\% Sugar Sol. & 1.1873 & 1.1876 & 21 & -0.02 \\
60\% Sugar Sol. & 1.2905 & 1.2931 & 21 & -0.21 \\
\hline
\end{tabular}




\section{APPENDIX C}




\section{APPENDIX C: PREPARATION OF THE SIMULANT}

The performance of the Pulsed Jet mixing and RFD sampling system was evaluated using three different slurries containing varying amounts of solids loading. Table C.1 lists the total amounts of solids taken to prepare the three slurries, the corresponding weight percent solids loading and specific gravity.

Table C.1. Amounts of the Total Solid and Liquid Phases Taken to Prepare The Slurries For The Pulsed Jet Mixer Testing, their Corresponding Solids Loading and Specific Gravity.

\begin{tabular}{lccc}
\hline & Slurry 1 & Slurry 2 & Slurry 3 \\
\hline Total Solid Phase (Lbs) & 15120 & 27919 & 40509 \\
Total Liquid Phase: Water at pH 12 (Lbs) & 70458 & 70690 & 70690 \\
Weight Percent Solids & $17.7 \%$ & $28.3 \%$ & $36.4 \%$ \\
Specific Gravity & 1.138 & 1.242 & 1.334 \\
\hline \hline
\end{tabular}

The volumes of the solids phase needed to compute the specific gravity of the slurry using the data in Table C. 1 was determined from the laboratory measured density of $3.2 \mathrm{~g} / \mathrm{cm}^{3}$ for the solids phase. Table C.2 lists the amounts of the individual chemical species used to make up the simulant based on the recipe Hanford Tank AZ-101/102 simulant recipe developed by Golcar et al. (2000). 
Table C.2. Amounts of the Individual Components Used to Make-up the Simulated Slurries Based on the AZ-101/102 Simulant Recipe Developed by Golcar et al. (2000).

\begin{tabular}{|c|c|c|c|c|c|c|}
\hline \multirow{2}{*}{ Chemical } & \multirow{2}{*}{ General Name } & \multirow{2}{*}{ Manufacturer } & \multirow{2}{*}{ Catalog Number } & \multicolumn{3}{|c|}{ Amount Taken (Lbs) } \\
\hline & & & & Slurry 1 & Slurry 2 & Slurry 3 \\
\hline $\mathrm{Fe}_{2} \mathrm{O}_{3}$ & Iron Oxide & Prince Manufacturing Co. & $07-5001$ & 2495 & 4902 & 6982 \\
\hline $\mathrm{Fe}_{2} \mathrm{O}_{3}$ & Syn. Red Iron Oxide & Prince Manufacturing Co. & $07-3728$ & 4308 & 8103 & 11886 \\
\hline $\mathrm{Fe}_{2} \mathrm{O}_{3}$ & Red Iron Oxide & Prince Manufacturing Co. & $07-2568$ & 1972 & 3198 & 4626 \\
\hline $\mathrm{Al}_{2}(\mathrm{OH})_{3}$ & Gibbsite & Schoofs & C-231 Gr. Wh. Hydrate & 1215 & 2291 & 3331 \\
\hline $\mathrm{Al}_{2}(\mathrm{OH})_{3}$ & Gibbsite & Schoofs & SpaceRite S-23 & 733 & 1369 & 2050 \\
\hline $\mathrm{Al}_{2}(\mathrm{OH})_{3}$ & Gibbsite & Schoofs & SpaceRite S-11 & 501 & 961 & 1412 \\
\hline $\mathrm{Al}_{2} \mathrm{O}_{3}$ & Boehmite & ALCOA & HiQ-10 Alumina & 1163 & 2032 & 2876 \\
\hline $\mathrm{Zr}(\mathrm{OH})_{4}$ & Zirconium Hydroxide & Magnesium Electron Inc. & FZO 922/01 & 1978 & 3660 & 5244 \\
\hline $\mathrm{Na}_{2} \mathrm{SiO}_{4}$ & Nepheline Syenite & Hammill \& Gillespie & Spectrum A 400 & 755 & 1403 & 2102 \\
\hline
\end{tabular}


PNWD-3054

BNFL-RPT-048, Rev. 0

\section{Distribution}

\begin{abstract}
No. of
Copies

OFFSITE

2 DOE/Office of Scientific and Technical Information
\end{abstract}

No. of

Copies

\section{ONSITE}

11 British Nuclear Fuels, Limited

E. Higginbotham

N. Hannigan (10)

BN-FL BN-FL

$5 \quad \mathrm{CHG}$

M. E. Johnson (4) H4-10

D. J. Washenfelder

H6-18

15 Pacific Northwest National Laboratory

\begin{tabular}{ll}
\hline J. R. Bontha (7) & K6-24 \\
G. R. Golcar & K6-24 \\
D. E. Kurath & P7-28 \\
E. V. Morrey & P7-28 \\
Technical Report Files (5) & K1-06
\end{tabular}

Distr. 1 